\title{
UNA LECTURA INSOLITA DE LA NORMA EH
}

\author{
(AN UNUSUAL READING OF "EH" SPANISH CODE)
}

\author{
Mariano Vázquez Espí \\ Instituto Juan de Herrera. Seminario de Diseño de Estructuras
}

$400-19$

\section{RESUMEN}

El lector encontrará aquí una pequeña historia de misterio e imaginación: un científico, el señor $K$, apartado de la universidad por razones que desconocemos, se ve obligado a acometer una investigación de índole técnica acerca de la posibilidad de estandarizar piezas de pórticos de hormigón armado. Desconocedor de la cultura práctica y de los trucos de los proyectistas avezados, escoge como instrumento de trabajo la instrucción EH-82. Voluntarioso y optimista, acomete la tarea con ilusión y con la esperanza de darle término prontamente.

$Y$, sin embargo, su cuidadosa lectura de la norma le llevará a descubrir contradicciones irresolubles entre sus diversos artículos, de suerte tal que, necesitado de la minuta de su cliente, tendrá que convencer a éste de la oportunidad de acometer una revisión cientifica de los actuales métodos de cálculo y comprobación, antes de que sea posible alcanzar alguna estandarización razonable.

El final es feliz: el señor $K$ consigue seguir trabajando para su cliente $y$, además, regresa a la universidad a través de un proyecto de la CAICYT.

\section{SUMMARY}

Our reader will find here a story about mistery and imagination: a scientist, Mister $K$, strangely not working at the University for reasons unknown to us, is forced by circumstances to overtake a technical research about possibilities of standarization of reinforced concrete frame members.

Ignoring the essentials of everyday knowhow and the tricks used by the most experienced designers, he chooses as a working tool the EH-82 spanish Code. Being wilful and optimistic, he undertakes his task with a great amount of illusion and the hope of a quick ending. However, after carefully reading the Code, he finds some unresolvable contradictions among its several items, in such a way that, needing desperately the economical counterpart of the assignment, he has no alternative but to convince his client of the apropriateness of undertaking a scientific revision of the present calculation and verification methods before reaching some reasonable level of standarization.

The story has a happy end: Mister $K$ succeeds in working on for his client and, furthermore, he finally comes back to the University thanks to a spanish CAICYT research project.

(Traducción de Carlos Verdaguer)

\section{PROLOGO}

El hecho de que en la Comisión 2 del Grupo Español del Hormigón exista un grupo específico para estudiar el CALCULO DE PORTICOS DE EDIFICACION EN COMPORTAMIENTO NO LINEAL (a cuyos miembros fue presentado por primera vez el siguiente texto), responde tanto a un puro interés científico como a un cierto malestar técnico. En efecto, si dispusiéramos de una normativa técnica satisfactoria, los miembros de este grupo se disolverian para engrosar las filas del de ANALISIS NO LINEAL, con el interés de simular (y por tanto predecir) cada vez mejor el comportamiento del hormigón armado en sus más íntimos detalles. Y tal sería incluso si de ello no se siguiera ningún cambio de importancia en la normativa técnica y, por tanto, en la forma de proyectar cotidianamente las estructuras de edificación. Sin embargo, y sin negar el interés de estu-

\section{ADVERTENCIA}

Todos los cálculos realizados en la ficción del mundo del señor $\mathrm{K}$ han sido realizados y comprobados por el autor, y se muestran en las sucesivas tablas. dios semejantes, la normativa técnica está lejos de resultar satisfactoria y, aún en un campo tan cotidiano y por tanto tan trivial como las estructuras de edificación, se hace necesaria una racionalización de la metodología del proyecto. Pensamos por ello que es necesario explicitar con claridad cómo y en qué medida es la normativa actual contradictoria o insuficiente. Para ello nos proponemos hacer una lectura un tanto insólita de la actual normativa'.

Necesitamos una lectura minuciosa y a la vez guiada por cierto interés práctico (al que toda norma responde). Igualmente, la lectura debería estar ausente de

\footnotetext{
1 El presente texto se presentó a los miembros del GT II-2 del Grupo Español del Hormigón, como documento de partida para discutir y fijar los objetivos del grupo a corto y largo plazo. Para ello era necesario explorar en qué dirección se encontrarian las soluciones a los problemas planteados, sin que se pretenda haberlas encontrado. Los modelos de análisis aqui expuestos deben verse, en consecuencia, como meras hipótesis de trabajo. De hecho, la discusión y debate del documento en el seno del grupo está pendiente y esperemos se celebre próximamente.
} 
prejuicios, por tanto debería tratarse de un lector virgen. Imaginemos para ello que éste sea el señor K. Se trata de un físico especializado en mecánica del sólido, que hasta ahora no ha abandonado el terreno de la reflexión científica. Nuestro hombre está pues familiarizado con temas que incluyen tanto la teoría de la elasticidad como la mecánica de fracturas, pero nunca ha proyectado estructura alguna. Sin embargo, un primo suyo, empresario emprendedor que se inició en el terreno de la construcción, pero que ha hecho incursiones en una multitud de campos industriales, le pide consejo sobre la posibilidad de estandarizar (industrializar) los pórticos de edificación o alguna de sus partes y, en especial, los de hormigón armado. Nuestro físico llega a un acuerdo con su primo en cuanto a honorarios y plazos y quedan en reunirse tres semanas más tarde. El señor $\mathrm{K}$ es una persona de sólidas costumbres y por nada trabajaria durante el fin de semana, así que pospone el inicio del trabajo hasta el lunes siguiente.

\section{PRIMERA SEMANA: LUNES}

Como primera tarea, el señor $\mathrm{K}$ se dirige a la universidad donde un antiguo compañero de estudios podrá ponerle al día acerca de normas y especificaciones hoy en uso, sobre el estado del arte, sobre los modos y costumbres con los que, en definitiva, se trabaja en el sector de la construcción. Allí, en efecto, puede hacerse con la norma EH-82, con algunos trabajos de investigación recientes, y conversando con su amigo logra hacerse una idea bastante cabal del problema que le espera. Sus primeras conclusiones caben en apenas un folio, pero espera que sean provechosas:

1. En piezas lineales (en pórticos, por tanto) se admite considerar tan sólo las deformaciones debidas a las tensiones normales paralelas a la directriz de la pieza, despreciándose tanto las debidas a las tensiones tangenciales como a las normales perpendiculares a la directriz.

2. Las cargas gravitatorias soportadas medidas por unidad de superficie varían entre límites bastante cer. canos, de modo que en una primera aproximación podrian considerarse constantes.

3. Aunque, en principio, las piezas de hormigón armado pueden diseñarse con una libertad bastante amplia, la práctica cotidiana muestra que ante problemas similares se llega siempre a soluciones similares, prácticamente iguales aún cuando no idénticas.

4. Sobre el papel, las comprobaciones que han de realizarse para validar un diseño determinado son innumerables. Es costumbre, sin embargo, que los técnicos experimentados reduzcan su número a unas pocas en los casos corrientes, en los cuales echan mano de sus experiencias anteriores.

Ya en su gabinete y después de una atenta y reflexiva lectura del índice de la EH-82 (en la que el señor K reconoce muchos de los conceptos), decide dirigirse directamente al título segundo. Si bien los capítulos IV y $\mathrm{V}$ le parecen una adecuada simplificación de las características de los materiales y de las acciones (aunque él está acostumbrado a usar ecuaciones constitutivas más "realistas"), el artículo 29 no deja de irritarle un tanto: ¿qué entender por "la determinación de las solicitaciones se efectuará con arreglo a los principios de la Mécanica Racional, complementados, en caso ne. cesario, por las teorías clásicas de la Resistencia de Materiales y de la Elasticidad"? Con esa información es, desde luego, imposible adivinar cómo los proyectictas calculan los momentos (lo que en definitiva es el problema planteado). Afortunadamente - piensa para sí- cuento con diagramas de tensión-deformación bien establecidos. El capítulo VI, las báses del cálculo, le resulta un poco difícil, pues es un tema olvidado para él, y sus apuntes universitarios han quedado ya desfasados. Según se desgranan durante la lectura los diversos artículos, subartículos, apartados y codas del capítulo VII, comprueba que, efectivamente, el número de comprobaciones de estados límites es bien grande y no parece estar, precisamente, bien ordenado. Con varios folios llenos de preguntas e incertidumbres, pero satisfecho con los resultados de su primera jornada, el señor $K$ se duerme pensando en la siguiente, que aparece ante él como un plácido día de finales de verano trabajando en su despacho, contemplando florecer las últimas rosas en el jardín.

\section{PRIMERA SEMANA: MARTES}

Al objeto de afianzarse en un tema tan nuevo para él, decide acometer la realización de algunos cálculos en torno a vigas apoyadas solicitadas por cargas gravitatorias. Para ello imagina una serie infinita de vigas separadas una distancia $V$ que cubren una luz L (Fig. 1). Sobre ellas apoyará un forjado que recibe las cargas. En estas condiciones cualquiera que sea la interpretación del artículo 29, las solicitaciones en cualquier sección de la viga pueden calcularse. ¿Qué viga (de qué sección, armadura, etc.) habrá de disponerse para resistirlas? Varias soluciones son posibles: puede disponerse desde una viga de gran canto, y estrecha y poco armada, hasta una losa muy finita pero muy ancha con mucha armadura (tan ancha que su ancho sea igual a V). La primera resultará muy rígida y se deformará po$\mathrm{co}$, mientras que la segunda puede que se deforme excesivamente. Además, si bien las dimensiones y armaduras de ambas y todas las intermedias se calculan para que resistan los momentos, es posible que no resistan apropiadamente los esfuerzos cortantes. Sin em- 


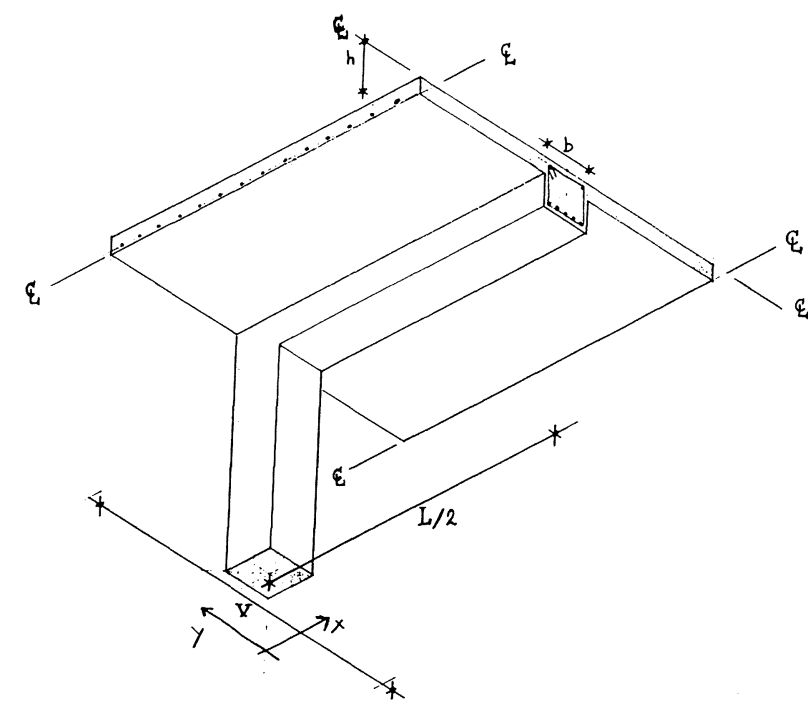

Fig. 1.-VIGAS APOYADAS: Se muestra desde abajo un módulo $v \times L / 2$ : La estructura se genera mediante una repetición por simetría en la dirección $x, y$ posterior repetición indefinida según $y, y$ en ambos sentidos. Si se sustituye el soporte por un apoyo puntual, no hay ninguna coacción al giro en el extremo.

bargo, el señor $\mathrm{K}$ decide postergar de momento las comprobaciones de cortante (igual que no considerará las deformaciones a él debidas). Así, para unas cargas y modulación dadas, calcula las dimensiones de una serie de vigas suficientemente resistentes y la flecha que tendrian en el estado límite de utilización.

Como precisamente el tema de la seguridad es bastante nuevo para él (mayoración de cargas, minoración de resistencias, valores característicos, etc.), se plantea, entre sus múltiples dudas, la siguiente cuestión. De una parte, las dimensiones que proporcionan una viga de resistencia suficiente, se calculan como si las cargas fueran 1,6 veces mayores y las máximas tensiones que pueden soportar el hormigón y el acero fueran 1,5 y 1,15 veces menores que las características, respectivamente. De otra, la comprobación de que la deformación es admisible se analiza bajo el supuesto de que la carga es la que es y que las máximas tensiones que podrían soportar los materiales son las características (aún cuando las tensiones efectivamente alcanzadas serán bastante más pequeñas, en virtud de la seguridad anterior). Lo que en jerga se denomina con precisión estado límite de utilización. Entonces, si una vez la estructura está siendo utilizada, la carga máxima prevista aumenta más allá de su valor, ¿la estructura se romperá al alcanzar la carga 1,6 veces ese valor, o por el contrario admitirá cargas superiores? Para satisfacer su curiosidad decide calcular también lo que llamará (por analogía) coeficiente de seguridad característico, esto es, la razón entre carga que produce la rotura cuando todos los coeficientes de ponderación son iguales a la unidad y la carga de servicio caracteristica que la estructura ha de soportar (naturalmente sin romperse) (Fig. 2).

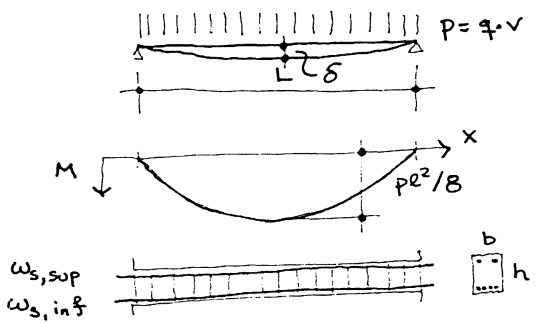

$$
\begin{aligned}
& \frac{M_{u d}}{b h^{2} f_{c d}}=\mu_{v d}\left(\omega_{s d}\right) \\
& \gamma_{f} \cdot \frac{p l^{2}}{8}=\mu_{u d} \cdot b h^{2} f_{c d} \\
& \frac{v}{b} \cdot\left(\frac{e}{h}\right)^{2}=8 \cdot \mu_{\text {ud }} \frac{f_{c d}}{q} \\
& \text { si } 11 \text { amamos } \lambda h=\ell / h ; \lambda b=v / b ; \text { y } k_{\text {DS0000 }}=8 \cdot \mu_{0 d} \cdot \frac{f_{C d}}{q} \\
& \text { podemos escritrir } \\
& \lambda_{k}^{2} \cdot \lambda_{b}=K_{\text {DISENO }} \\
& \text { Si se elige un cauto } h \text { (o ond esbelta } \lambda h \text { ) } \\
& b=\frac{\lambda h^{2}}{k_{D \text { DENO }}} \cdot v
\end{aligned}
$$

\section{ANAWISIS}

$$
\begin{aligned}
\text { si } \gamma_{f}=\gamma_{c}=\gamma_{s} & =1 \quad \omega_{s k}=\omega_{s d} \cdot \frac{\gamma_{s}}{\gamma_{c}} \Rightarrow \mu_{u k} \neq \mu_{\text {od }} \\
\frac{M_{u k}}{b k^{2} f c k} & =\mu_{u k}\left(\omega_{s k}\right) \\
\mu_{u k} & =\frac{q_{u k} \cdot v l^{2}}{8} \\
q_{u k} & =\frac{8 \cdot \mu_{u k} \cdot f_{c k}}{\lambda_{b} \cdot \lambda_{h}^{2}}=\frac{8 \cdot \mu_{u k} \cdot f_{c k}}{k_{\text {DISE J J }}}
\end{aligned}
$$

Colled la viga es simétrica

$$
\begin{aligned}
\delta & =\int_{0}^{l / 2} c \cdot x \cdot d x=\int_{0}^{l / 2} \frac{1}{R} \cdot x d x= \\
& =l \int_{0}^{l / 2} \frac{h}{R} \cdot \frac{L}{h} \cdot \frac{x}{L} d\left(\frac{x}{L}\right)= \\
& =\lambda_{h} \cdot L \int_{0}^{0.5}\left(\varepsilon_{s}-\varepsilon_{c}\right) \frac{h}{d} \frac{x}{L} d\left(\frac{x}{L}\right) \\
\frac{f}{L}=\frac{\delta}{L} & =\lambda_{h} \int_{0}^{0.5}\left(\dot{\varepsilon}_{s}-\varepsilon_{c}\right) \frac{h}{d} \frac{x}{L} d\left(\frac{x}{L}\right)
\end{aligned}
$$

Fig. 2.-ALGORITMO PARA LAS VIGAS APOYADAS 
Tabla $1\left({ }^{*}\right)$. VIGAS APOYADAS. DISEÑO ESTRICTO.

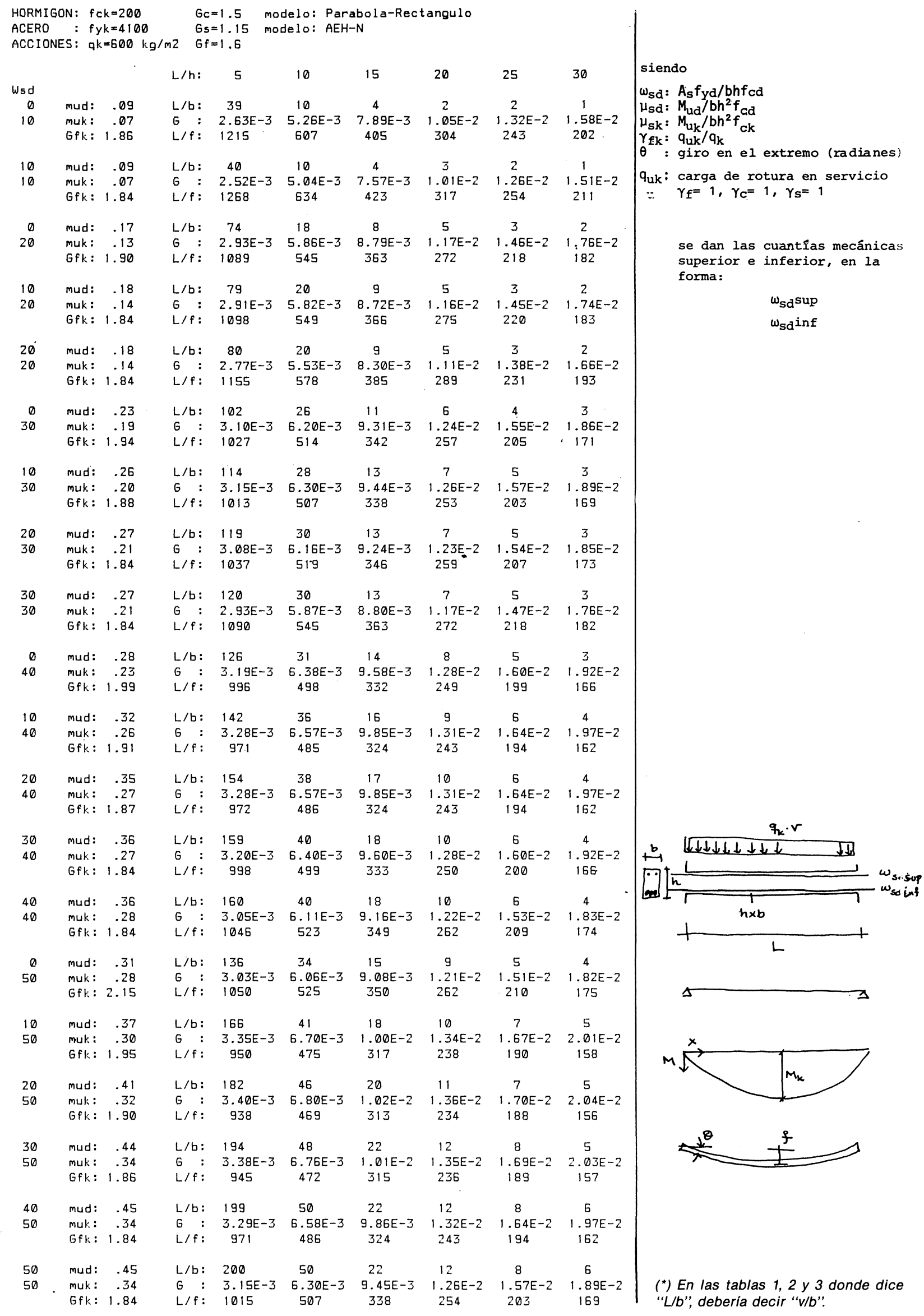


Puesto que, además, tales estructuras cumplen ciertas leyes de semejanza, puede resumir sus cálculos en la tabla 1.

Dos cosas le llaman poderosamente la atención: De una parte, la flecha depende básicamente de la proporción entre el canto y la luz. Es decir, dadas dos vigas de sección distinta, basta que ambas estén dimensionadas para resistir estrictamente sus cargas y que tengan la misma esbeltez, para que sus flechas relativas (a la luz), sean aproximadamente idénticas. Pero, además, si el modelo utilizado fuera fiable, cabría concluir que la estructura efectivamente realizada (en la que se tiene constancia de que los materiales resisten las tensiones características) no sólo resiste más que la carga de cálculo (la carga de rotura prevista en el proyecto), sino que la carga de rotura característica es variable con las cuantías de armado. Para seguir avanzando se hace necesaria una nueva visita a la Universidad, piensa el señor $\mathrm{K}$.

\section{PRIMERA SEMANA: MIERCOLES}

De nuevo en la Universidad, el señor $\mathrm{K}$ puede aclarar muchas de sus dudas y preocupaciones, a saber:

1. La interpretación comúnmente admitida del irritante artículo 29 consiste en calcular los momentos (las solicitaciones) como si no hubiera armaduras y el hormigón fuese perfectamente elástico. Así, para armar una viga doblemente empotrada, el proyectista partirá de los conocidos momentos de empotramiento perfecto.

2. No obstante, la determinación de la resistencia de la sección armada (y aún de su deformación, es decir, su curvatura) se realiza de acuerdo con el diagrama de tensión-deformación correspondiente. Es decir, tal y como el señor $\mathrm{K}$ había operado para el caso de la viga apoyada.

Sin embargo, su amigo le advierte que si bien el diagrama parábola-rectángulo se considera apropiado para determinar resistencias (momentos últimos), a la hora de calcular flechas, los proyectistas prefieren otros diagramas, en el convencimiento de que el P-R subestima la rigidez del hormigón en situaciones de servicio. Con respecto a los cálculos del señor $\mathrm{K}$, este hecho afecta a los valores absolutos de L/f calculados, pero no demasiado a las relaciones entre esos valores para distintas vigas.

3. De ahi se sigue la validez de las conclusiones del señor K: vigas con distinta rigidez "elástica" (es decir, con distinto ancho e idéntico canto) resultan ser aproximadamente igual de rígidas (es decir, tienen aproximadamente la misma flecha).
4. Por último, si se opera según la normativa, sólo se obtienen niveles de seguridad iguales en los estados límites últimos. Una vez las estructuras construidas (correctamente), las que tengan menos armadura de compresión soportarán mayores cargas, puesto que los coeficientes de minoración de los materiales penalizan más el hormigón que el acero, en correspondencia con la menor fiabilidad de aquél.

De vuelta a casa, en el autobús, el señor K ya se imagina el cálculo de las vigas empotradas.

La cosa no puede ser más simple, partiendo de los momentos de empotramiento perfecto correspondientes a la carga de rotura (con los coeficientes de seguridad adecuados) se determinan vigas capaces de resistirlos. Al igual que hiciera con las apoyadas, haciendo.los coeficientes de minoración de los materiales y los de ponderación de las cargas iguales a 1, pueden determinar la flecha. Y a pesar de las advertencias de su amigo, y para no complicar de momento más los cálculos usará para ello el diagrama parábola-rectángulo con valores característicos. "¡Sólo son cálculos preliminares!", piensa. Para que la analogía sea perfecta, con los momentos de rotura "característicos" (es decir, con la resistencia de los materiales sin minorar) se calcula la carga de rotura "característica". Para representar la condición de empotramiento (giro nulo en el apoyo), utilizará el mismo esquema de las vigas apoyadas, salvo que ahora la estructura no sólo será indefinida en la dirección perpendicular al plano de las vigas, si no que también lo será en su dirección, de modo que vigas y forjado sean continuos. En tal caso, dada la repetición y la simetría de la estructura los planos verticales que pasan por los ejes de los soportes han de permanecer verticales tras la deformación (Fig. 3).

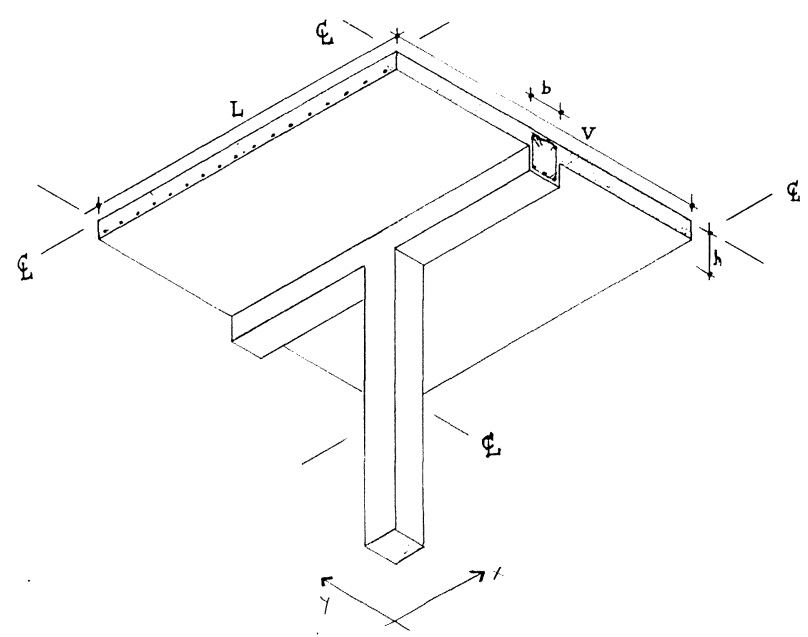

Fig. 3.-VIGAS EMPOTRADAS: Se muestra desde abajo un módulo $L \times v$ : puesto que el módulo es simétrico, se repite indefinidamente por yuxtaposición en las dos direcciones $x$ e y. Si se analizan los movimientos de un plano vertical que contenga el eje del soporte y sea paralelo a cualquiera de los ejes, se ve que, debido a la simetría y a la infinitud de la estructura, hay tantas razones para que gire hacia la izquierda como para que gire a la derecha: de hecho no gira, permaneciendo vertical durante el proceso de carga. 


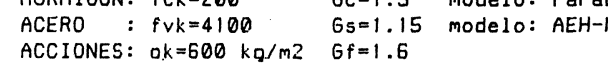

$$
\text { ting }
$$

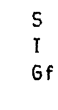$$
\text { I }
$$ 


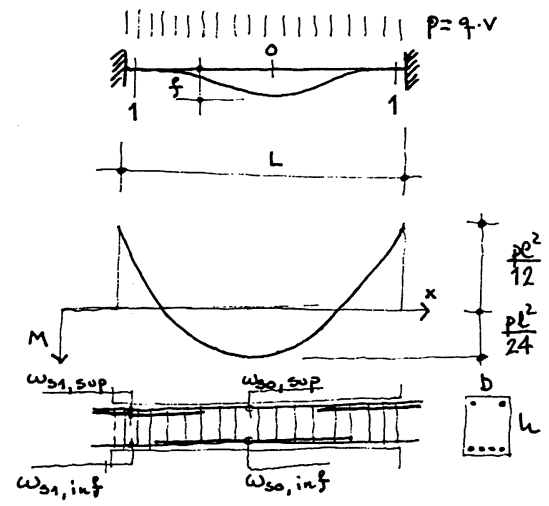

CALCULO

Para ads cusatía wadn (sup: inf)

$\frac{M_{u d_{1}}}{{b h^{2} f_{c d}}_{1}}=\mu_{u d_{1}}\left(\omega_{\text {sd1 }}\right)$

Cono el diseĩo es estricto, se determinaŕ $\omega_{s d \phi}$ de

forma que $\frac{M_{\text {udd }}}{b^{2} h_{\text {ted }}}=\frac{1}{2} \mu_{\text {ud }}\left(\omega_{s+1}\right)$

Eutouces $\gamma_{f}\left(\frac{p e^{2}}{12}+\frac{p e^{2}}{24}\right)=\gamma_{f} \cdot \frac{p e^{2}}{8}=\left\{\mu_{w d}\left(\omega_{s s h}\right)+\mu_{w d}\left(\omega_{s d \sigma}\right)\right\} \cdot b h^{2} f_{d d}=$ $=\frac{3}{2} \mu_{0 d}\left(\omega_{s+1}\right) \cdot b h^{2} f_{e d}$

Si llamamos a

$$
K_{\text {DISENO }}^{\prime}=8 \gamma^{\prime} \mu_{\text {Od }}\left(\text { cosd }_{1}\right) \cdot \frac{3}{2} \frac{f_{C d}}{q_{k}}
$$

entonces la condición de resistencia re expresa

$$
\lambda^{2} h \cdot \lambda_{b}=k_{\text {DISENO }}^{\prime}
$$

Analisis

Razonando igual que coen las vigas apoyadas

$$
q_{u k}=\frac{8 \cdot\left\{\mu_{u k}\left(\omega_{\text {sk } 1}\right)+\mu_{u k}\left(\omega_{\text {sk }}\right)\right\} f_{c k}}{k_{\text {Disento }}^{\prime}}
$$

La deformaciea

$$
\frac{f}{L}=\lambda_{h} \int_{0}^{0.5}\left(\varepsilon_{s}-\varepsilon_{c}\right) \frac{h}{d} \frac{x}{L} d\left(\frac{x}{L}\right)
$$

pero integrado $\varepsilon_{3}, \varepsilon_{c}$ car el merso diagrana de moveutos.

FIg. 4.-ALGORITMO "ELASTICO" PARA LAS VIGAS EMPOTRADAS

Viendo la cosa así de clara, el señor K poco tarda en reescribir los programas de la viga apoyada para el cálculo de las empotradas (Fig. 4). Y al poco obtiene los resultados buscados que se muestran en la tabla 2 .

De una primera inspección, comprueba que las propiedades de las vigas apoyadas se reproducen cualitativamente en las doblemente empotradas: las flechas permanecen relativamente constantes al variar el ancho manteniendo constante el canto. Por comparación con la tabla 1 ve además que la seguridad característica varía, de igual modo, con la estrategia de armado (cuantía de la armadura de compresión), presentando similares valores. Sin embargo, esperaba obtener va- lores de flechas notablemente menores: los calculados sólo son apenas valores mitad de los que corresponderían a la viga apoyada análoga. Ante la inseguridad, decide echar unos números. Para ello compara una viga apoyada y otra empotrada de igual canto, cuantia máxima y carga; sólo distintas en el ancho por tanto (Fig. 5). Aplicando los teoremas de Mohr y establecien-

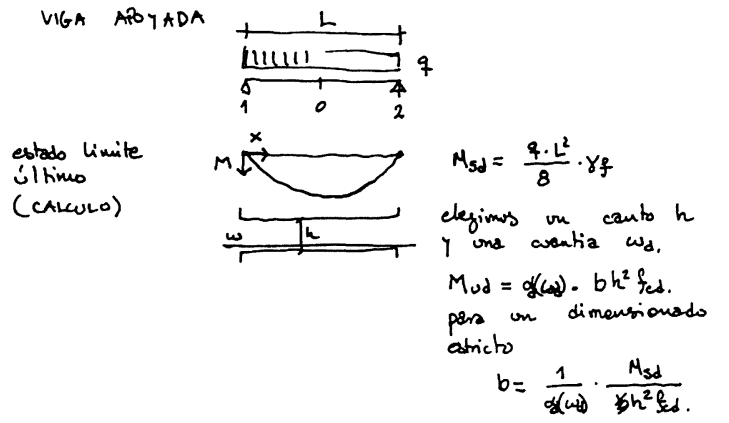

$$
\begin{aligned}
& \begin{array}{l}
\text { estedo limite } \\
\text { de servicio } \\
\text { (ANALISIS) }
\end{array} M_{S k}=\frac{q L^{2}}{8} \\
& c_{\max }=\frac{M_{s k} \varepsilon_{c a d}}{k_{s e c} \cdot b k^{3} f_{c x}}=\frac{k_{k k}}{k_{c b s}} . \\
& \omega_{n}=\omega_{d} \cdot \frac{r_{s}}{Y_{c}} \\
& k_{s c c}=\frac{r_{c}}{b}=\frac{M_{s} / b k^{2} f_{c k}}{n / R} \cdot \frac{1}{R}=c \\
& k_{\text {bec }} \simeq \text { cte un periodo eliastico } \\
& \begin{array}{l}
\theta \simeq \frac{2}{3} C_{\text {max }} \cdot \frac{1}{2} L=\frac{1}{3} C_{\text {max }} \cdot L \\
f \simeq \frac{2}{3} C_{\text {max }} \cdot \frac{1}{2} L \cdot \frac{5}{8} \cdot \frac{1}{2} L=\frac{5}{48} L^{2} \cdot C_{\text {max }}
\end{array}\left\{\begin{array}{l}
\theta \simeq \frac{1}{3} \cdot \frac{h}{R_{\min }} \cdot \lambda h \\
\frac{f}{L} \simeq \frac{5}{18} \cdot \frac{h}{R_{\operatorname{man}}} \cdot \lambda h
\end{array}\right.
\end{aligned}
$$

VIGA EMPO TRADA.

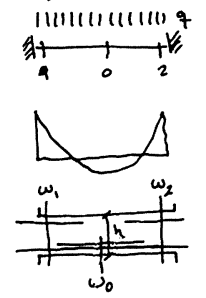

estado limite

de rervicio

(ANALISIS)

$M_{s K_{1}}=\frac{q L^{2}}{12}=\frac{2}{3} M_{s k}$

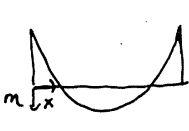
lesterd limite ultimo
$M_{2 d_{1}}=\frac{q L^{2}}{12} \cdot \gamma_{f}$
$\mu_{s d o}=\frac{q L^{2}}{24} \cdot Y_{f}$
desimos on canto igual (h)
$y$ wrutias tales que
$\omega_{1}=\omega_{d}$

$M_{u d t}=\alpha(w d)-b^{\prime} k^{2}$ fed

pre un dimousionamiento

pertricto

$b^{\prime}=\frac{1}{\alpha\left(w_{b}\right)} \cdot \frac{M_{8 d_{1}}}{h^{2} k_{d d}}=\frac{2}{3} b$

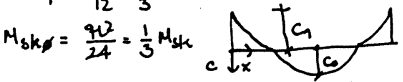

$c_{1}=\frac{M_{\delta m}}{R_{s e c} \cdot b^{\prime} k^{3} \ell_{c k}}=$

$=\frac{3 / 3 M_{s k}}{k_{\text {sec }} \cdot \frac{2}{3} b^{3} k_{k}}=C_{\text {max }}$.

Cove or lis condiciones de contrus ha de cer $\theta_{1}=0$, se teutrí (ax poido

$\begin{aligned} & \text { distico) } \\ & \theta_{1}\end{aligned} \frac{2}{3}\left(c_{\text {max }}+c_{0}\right) \cdot \frac{1}{2} L-\frac{1}{\text { max }} \cdot \frac{1}{2} L=0$

6 qe determina 6

$C_{0}=C_{\max } \cdot \frac{1}{2} L \cdot \frac{32}{2 L} C_{\max }=\frac{C_{\max }}{2}$

Eutouces

$f^{\prime} \simeq \frac{x}{3}\left(\frac{x}{2} C_{\max }\right) \cdot \frac{1}{2} L \cdot \frac{5}{8} \cdot \frac{1}{2} L-C_{\max } \cdot \frac{1}{2} L \cdot \frac{1}{4} L=$

$=\frac{1}{32} \cdot C_{\max } \cdot L^{2} \Rightarrow \frac{\rho^{\prime}}{L} \simeq \frac{1}{32} \cdot C_{\max } \cdot L$

determinado b re calwiarion

las cuantion $\omega_{0}$ tales que Mudp $=M_{\text {sd }}$. En geverel seriar $\omega_{0} \leq \frac{\omega_{d}}{2}$. Pro

pare lo que aqui interesa

ho es necerasio)

$$
\begin{aligned}
& \text { Comparacion } \\
& \frac{f / L}{f^{\prime} / L}=\frac{3 / 48}{1 / 32}=\frac{10}{3} * ! 1
\end{aligned}
$$

FIg.5-CALCULO APROXIMADO DE LA RELACION ENTRE LAS FLE. CHAS DE UNA VIGA APOYADA Y UNA EMPOTRADA ANALOGA: Se trata de vigas soportando la misma carga; además de la cuantia de la sección central de la apoyada es igual a la de los extremos en la empotrada, de modo que en la sección central, esta última, tiene cuan. tia mitad. 
do algunas simplificaciones, llega con facilidad a que la flecha de la apoyada habría de ser 5/48 del producto $c \times L^{2}$, siendo $c$ la curvatura máxima del vano. En el caso de la empotrada tiene que determinar primero las curvaturas de extremo y de vano. La primera de ellas es igual a c, puesto que se trata de una sección de igual cuantía que la sección del vano de la viga apoyada. Para determinar la curvatura en el vano aplica la condición de que el giro en el extremo habrá de ser nulo. $\mathrm{Pa}$ ra ello dicha curvatura habrá de ser $\mathrm{c} / 2$. Y, por último, la flecha será entonces $1 / 32$ de $c \times L^{2}$. $Y$ la relación entre la flecha de la apoyada y la de la empotrada es entonces como 10 es a 3. Las flechas de la empotrada debian ser menores que la tercera parte de las de la apoyada. "iEsto contradice al sentido común!", exclama para sí el señor K. Pensando que sin duda se trata de un error propio, el día se le escapa intentando encontrarlo, sin obtener éxito alguno. En las primeras horas de la madrugada, preso de un fuerte insomnio, no puede por menos que maldecir su suerte.

\section{PRIMERA SEMANA: VIERNES}

Recordando en el desayuno las malas horas pasadas durante la noche, el señor $\mathrm{K}$ se propone firmemente no dejarse llevar por la desesperación y proceder con calma y limpieza. La determinación de las armaduras necesarias para resistir la carga no ofrecen ninguna dificultad: puesto que los momentos son conocidos (los de empotramiento), con el valor de la carga de cálculo se determina el valor del momento en el vano, y se disponen armaduras tales que resistan precisamente esos momentos. La carga de rotura "característica" no ofrece tampoco dificultad alguna: basta con calcular los momentos que resisten las armaduras con la resistencia de los materiales sin minorar, y calcular la carga que corresponde a tales momentos. Ahora, sin efectuar ponderación alguna ni en el valor de la carga, ni en los de las resistencias, con los momentos de servicio, que estarán en la misma proporción que los anteriores, obtiene en cada punto la curvatura correspondiente al momento actuante y, finalmente, la doble integral de la curvatura a lo largo de media viga (pues es simétrica) será el valor de la flecha en mitad del vano. Salvo los mo. mentos nada ha cambiado respecto a la viga apoyada. No viendo ninguna incorrección, el señor K calcula los giros en los extremos de dos de las vigas, una apoyada, empotrada la otra, por simple integral de la curvatura de media viga, para ver si guardan también la proporción de las flechas. Y, efectivamente, así es.

“Pero, ¿¡cómo es posible tamaña estupidez!? ¡El giro de la empotrada tiene que ser nulo! ¡¿A qué demonios he de calcularlo!?' Y, sin embargo, habiéndose dejado llevar por su desesperación había descubierto la midad de su problema: fuera como fuese ese giro no era nu. lo. Vuelta con las comprobaciones empleando ahora otro método: "Veamos," se dice el señor K, "he tomado los momentos de empotramiento perfecto para la carga característica, en cada punto he calculado la curvatura, he sumado ésta a lo largo de la directriz, y el valor que obtengo es la diferencia entre los giros en los apoyos. Si ambos fueran nulos, la suma también lo sería, pero no lo es... Hmm! ¿Qué es lo que está equivocado?... ¡Pues claro! ¡Seré ingenuo! ¡Son los momentos los que están equivocados!: Si los escojo de modo que una pieza de sección constante y material elástico cumpla la condición de giro nulo en el extremo, no puedo luego calcular deformaciones considerando secciones de hormigón armado variables a lo largo de la luz. No puedo calcularlas, al menos, con esos momentos. Si quiero hacer esto (y he de hacerlo según la normativa) tendré primero que averiguar qué momentos aseguran en ese caso que el giro es efectivamente nulo. Sólo con esos momentos (ahora si de empotramiento perfecto) tiene sentido calcular la flecha. Ahora me explico lo de las "limitaciones prácticas relativas a flechas": ¡Nadie calcula realmente deformaciones ni flechas! Todos calculan el canto para que la comprobación no sea necesaria."

Releyendo los comentarios al articulado, el señor K se reconoce a sí mismo que estuvo poco atento, porque el exégeta avisaba, siquiera oscuramente, de este problema cuando comenta: "El método general de cálculo de flechas consiste en establecer la ley de variación de la curvatura de la pieza, determinando después la deformada por doble integración." $Y$ "establecer la ley de variación de la curvatura" no es sino un modo elíptico de decir "determinar los momentos de extremo", puesto que, una vez establecidos éstos correctamente (cumpliendo las condiciones de extremo), las cargas determinan la ley de variación de los momentos, y con ésta y la ley de variación de las armaduras queda determinada la ley de variación de la curvatura. "Basta por hoy".

\section{SEGUNDA SEMANA: LUNES}

Después de las largas horas del fin de semana, arrimado a la orilla sin que las truchas se animaran a saborear su anzuelo, el señor $\mathrm{K}$ vuelve al gabinete con el ánimo recobrado: "Ya se fue la semana", advierte. "Sólo he perdido un día", piensa para consolarse.

Su problema de cálculo no le es en absoluto desconocido: no es la primera vez que se las ve con análisis complejos. Así que reescribe las rutinas de cálculo de modo que determinen, para cada carga, la ley de momentos que cumple la condición de que el giro en los apoyos sea nulo (Fig. 6). Como la rutina es por com- 


$$
\begin{aligned}
& \text { deformacia de la cunpotrada } \\
& \underbrace{\theta=\phi 1} \\
& \theta=\frac{V}{2} \int_{0}^{k / 2} c d x=\int_{0}^{L / 2} c d x=\left.\lambda h \cdot I_{c}\right|_{0} ^{1 / 2}=\varnothing \\
& \zeta \text { renisar CONDicion }
\end{aligned}
$$

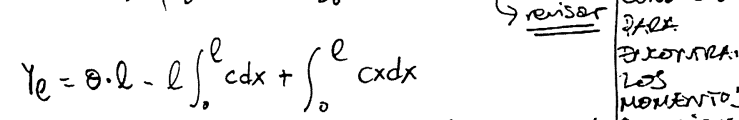

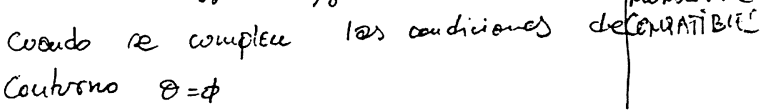

$$
\begin{aligned}
& y_{e}=-e \int_{0}^{e} c d x+\int_{0}^{e} c x d x \\
& \text { Son } e=\frac{L}{2} \\
& y_{\frac{L}{2}}=-\frac{L}{2} \int_{0}^{L / 2} d x+\int_{0}^{L / 2} c x d x \\
& \text { pero por lo misno } \int_{0}^{L / 2} c d x=0 \\
& \text { por tanto } y_{\frac{L}{2}}=\int_{0}^{L / 2} c x d x=d y=\frac{x}{c o t} \\
& =\lambda_{h} \cdot \frac{L}{h} \int_{0}^{0,5} \frac{h}{R} \frac{x}{L} d\left(\frac{x}{L}\right) \\
& \frac{Y_{L / 2}}{L}=\left.y_{4} \cdot \lambda h \cdot I_{C x}\right|_{0} ^{05} \rightarrow \text { reviser }
\end{aligned}
$$

FIg. 6.-ECUACION DE COMPATIBILIDAD DE DEFORMACIONES PARA LA VIGA EMPOTRADA REPRESENTADA MEDIANTE UN ELEMENTO UNIDIMENSIONAL: Se trata en esencia de una aplicación de los teoremas de Mohr pero sin postular la constancia del módulo de elasticidad ni la homogeneidad de la sección.

pleto general, la empleará igualmente para determinar la carga de rotura. Precisa, con todo, diseñar (calcular) las armaduras de las vigas para poder analizar sus deformaciones. Parte para ello (a falta de otros mejores) de los mismos momentos que antes, los elásticos de empotramiento perfecto.

Se ve entonces en la necesidad de distinguir entre momentos resistentes y momentos últimos. En efecto, puesto que ha de calcular las armaduras antes de efectuar el análisis, debe suponer unos momentos a resistir en cada sección de la pieza: éstos son los clásicos de empotramiento que decide llamar resistentes. Ahora, ya sea en el estado límite de cálculo o en el de utilización, comenzará a simular un proceso de carga hasta alcanzar la rotura, es decir, la carga última de cálculo. Los momentos solicitantes en ese instante serán los momentos últimos o de rotura de la viga. "Además, en el proceso de carga en servicio, convendrá guardar los momentos solicitantes que actúan cuando la carga iguala a la carga de servicio ("característica»): éstos serán los máximos momentos a soportar durante la vida útil de la estructura, y será con ellos con los que calcularé la flecha", razona el señor K.
El programa será ahora bastante más lento, asi que dejándolo todo en funcionamiento, abandona el ordenador a su suerte, no sin la secreta esperanza de que al día siguiente pudiera analizar ya los resultados.

\section{SEGUNDA SEMANA: MARTES}

Y efectivamente, los resultados alli estaban (tabla 3), aunque no dejarán de ser algo inquietantes: ninguna de las vigas estudiadas alcanzaba la carga de rotura para la que habia sido proyectada, todas (en el estado límite último) rompían antes. Adicionalmente, la carga de rotura "característica", siendo mayor que la de cálculo, quedaba lejos de alcanzar los valores de una viga apoyada análoga. Todavía más: si bien los momentos resistentes estaban en la proporción 2/1, tanto los últimos como los característicos estaban en la razón $3 / 1$.

El día pasó en comprobaciones y búsquedas de errores, pero allí no había gato encerrado (o gazapo). Volvió de nuevo al álgebra para realizar una aproximación, aunque grosera, y comprobar si los resultados eran más o menos fiables. Con sólo suponer que los momentos resistentes son proporcionales a las cuantías, y que las razones entre momento solicitante y cuantía son, a su vez, proporcionales a las curvaturas (suposiciones ambas que no le parecian demasiado disparatadas), Ilegó a la conclusión de que los momentos últimos o característicos debían rondar la proporción 4/1, lo que desde luego permitía predecir una carga de rotura del orden de 5/6 de la prevista (Fig. 7).

Pensar que el algoritmo utilizado era correcto y que varias generaciones de proyectistas habian sobreestimado la resistencia de sus estructuras era demasiado fuerte como para quedarse tranquilo. Para aumentar la confusión, en las referencias que había fotocopiado en la universidad, las cargas de rotura obtenidas experimentalmente no podían compararse con facilidad con sus resultados: en el experimento no cabia hablar de estado límite último, puesto que la minoración de la resistencia de los materiales no podía minorarse: era la que era. Cabia, con todo, concluir provisionalmente que:

1. No conocía referencia alguna (ni su amigo universitario le habia hecho comentario alguno al respecto), que pusiera en duda que, si se arma una pieza para resistir el esquema de momentos para el empotramiento perfecto "elástico", se alcanzará la carga de rotura.

2. La norma EH-82 (tal y como la habia él interpretado, y pensaba que lo había hecho correctamente) no permitía explicar ni predecir que efectivamente se alcance. 
Tabla $3\left({ }^{*}\right)$. VIGAS DOBLEMENTE EMPOTRADAS SIMETRICAS. CARGAS COMPATIBLES. APOYOS DE LONGITUD NULA. VIGA EMPOTRADA: $67: 33$ $\begin{array}{lll}\text { HORMIGON: } f c k=200 & G c=1.5 & \text { modelo: } \\ \text { ACERO : f } f y=4100 & G 5=1.15 & \text { modelo } 0: \text { AEH-N }\end{array}$

ACCIONES: $q k=600 \mathrm{~kg} / \mathrm{m} 2 \quad 6 f=1.6$

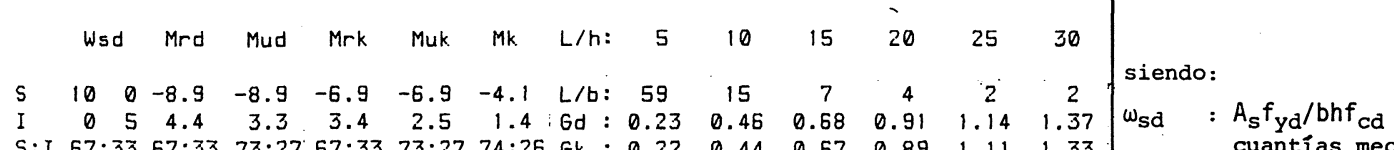

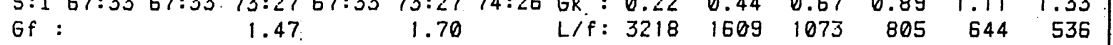
$\begin{array}{lrrrrrrrrrrrrrr}\mathrm{S} & 10 & 0 & -9.0 & -9.0 & -7.0 & -7.0 & -4.2 & \mathrm{~L} / \mathrm{b}: & 60 & 15 & 7 & 4 & 2 & 2 \\ \mathrm{I} & 10 & 5 & 4.5 & 3.3 & 3.5 & 2.5 & 1.5 & 6 d: & 0.23 & 0.45 & 0.68 & 0.91 & 1.13 & 1.36\end{array}$

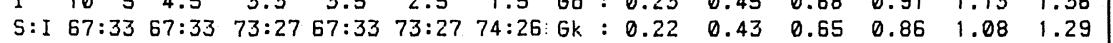
$\begin{array}{lllllllllll}\text { Gf }: & 1.46 & 1.68 & \text { L/f: } & 3293 & 1646 & 1098 & 823 & 659 & 549\end{array}$

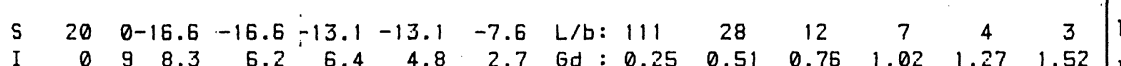
$\begin{array}{lccccccccccccc}\text { I } & 0 & 9 & 8.3 & 6.2 & 6.4 & 4.8 & 2.7 & 6 d: 0.25 & 0.51 & 0.76 & 1.02 & 1.27 & 1.52 \\ \text { S:I } & 68: 32 & 67: 33 & 73: 27,67: 33 & 73: 27 & 74: 26 & G K & : 0.25 & 0.49 & 0.74 & 0.98 & 1.23 & 1.47\end{array}$ $\begin{array}{llllllllll}\text { Gf }: & 1.47 & 1.73 & \text { L/f }: & 2917 & 1459 & 972 & 729 & 583 & 486\end{array}$

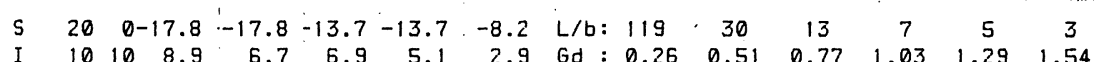
S:I $67: 33 \quad 67: 33 \quad 73: 27 \quad 66: 34 \quad 73: 27 \quad 74: 26 \quad 6 k: 0.26 \quad 0.52 \quad 0.78 \quad 1.04 \quad 1.30 \quad 1.56$ $\begin{array}{lllllllllll}\text { Gf }: & 1.47 & 1.68 & \mathrm{~L} / \mathrm{f}: & 2895 & 1447 & 965 & 724 & 579 & 482\end{array}$

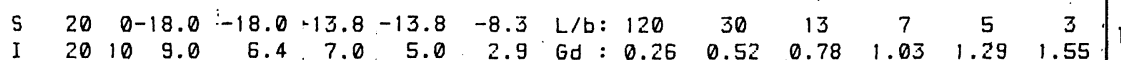

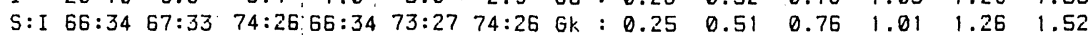
$\begin{array}{llllllllll}\text { Gf }: & 1.45 & 1.67 & {[/ f:} & 2987 & 1494 & 996 & 747 & 597 & 498\end{array}$

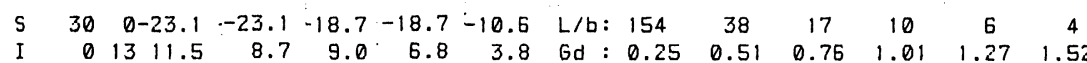

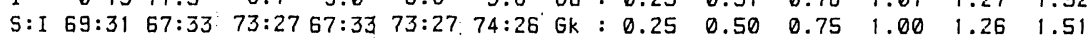
$\begin{array}{llllllllll}\text { Gf }: & 1.47 & 1.77 & L / f: & 2770 & 1385 & 923 & 693 & 554 & 462\end{array}$

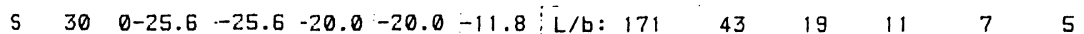

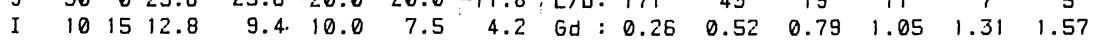
S:I $67: 33 \quad 67: 33 \quad 73: 27 \quad 67: 33 \quad 73: 27 \quad 74: 26 \quad G k: 0.26 \quad 0.52 \quad 0.78 \quad 1.04 \quad 1.30 \quad 1.56$

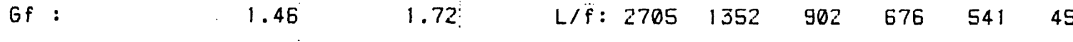

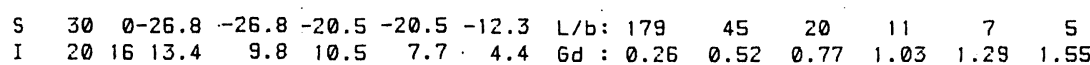

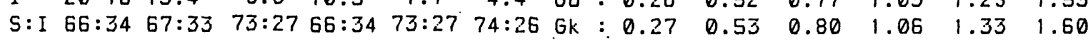

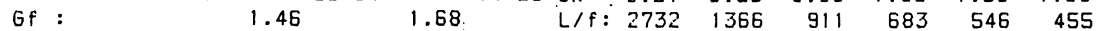
S $\quad 30 \quad 0-27.0-27.0-20.7-20.7-12.5 \quad L / b: 180 \quad 45 \quad 20 \quad 11 \quad 7 \quad 5$ $\begin{array}{lllllllllllllll} & 30 & 16 & 13.5 & 9.4 & 10.6 & 7.5 & 4.4 & \text { Gd } & 0.26 & 0.53 & 0.79 & 1.06 & 1.32 & 1.59\end{array}$

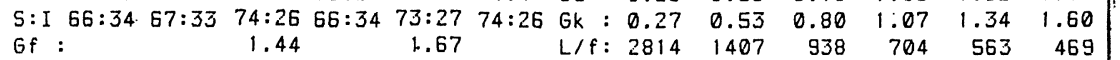

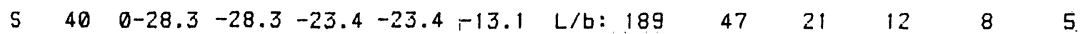

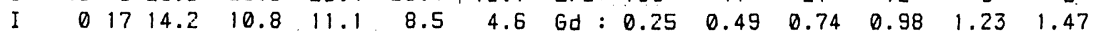
S:I $71: 29 \quad 67: 33 \quad 72: 28 \quad 68: 32 \quad 73: 27 \quad 74: 26$ GK $: \begin{array}{lllllll}0.25 & 0.49 & 0.74 & 0.98 & 1.23 & 1.47: 0\end{array}$

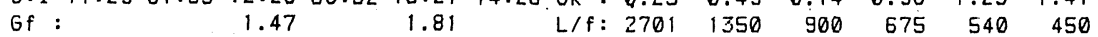

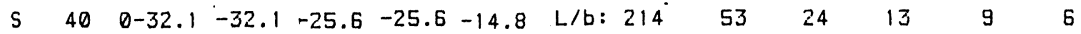

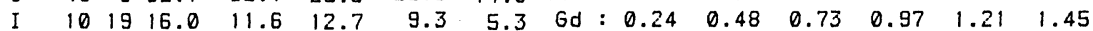

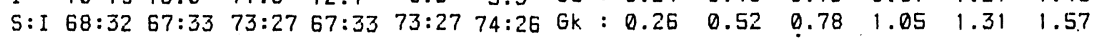
$\begin{array}{lllllllll}G f: & 1.45 & 1.74 & L / f: 2610 & 1305 & 870 & 652 & 522 & 435\end{array}$

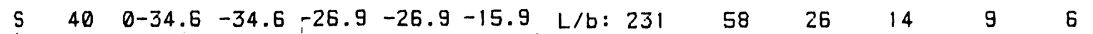
$\begin{array}{lllllllllllllll}\text { I } & 20 & 21 & 17.3 & 12.3 & 13.7 & 10.0 & 5.7 & \text { Gd } & : 0.24 & 0.47 & 0.71 & 0.95 & 1.19 & 1.42\end{array}$

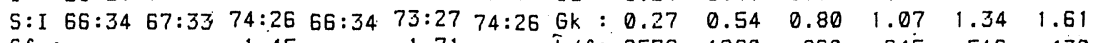

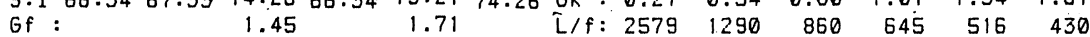
S $\quad 40 \quad 0-35.8-35.8-27.4-27.4-16.5, L / b: 239 \quad 60 \quad 27 \quad 15 \quad 10 \quad 7$

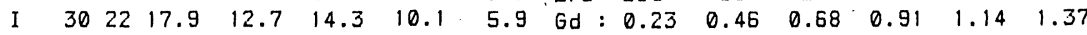

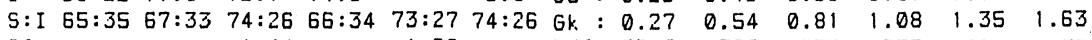

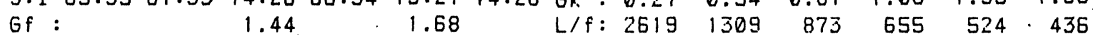
$5 \quad 40 \quad 0-35.9-35.9-27.5-27.5-16.6 \quad L / b: 240 \quad 60 \quad 27 \quad 15 \quad 10 \quad 7$

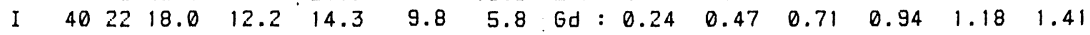

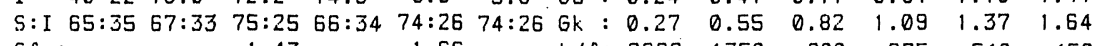

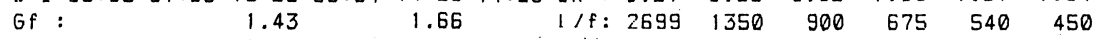

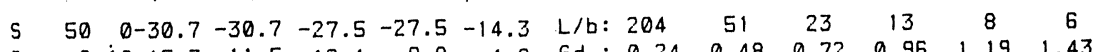

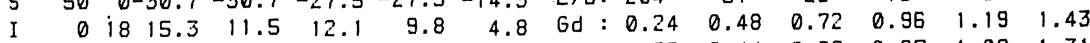

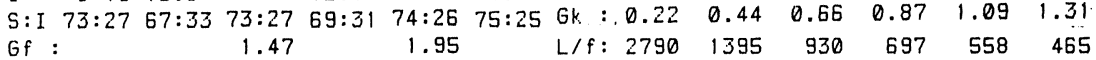

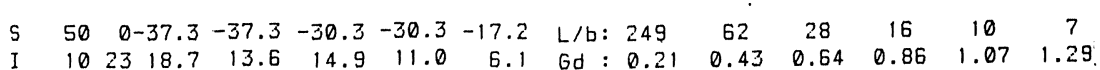

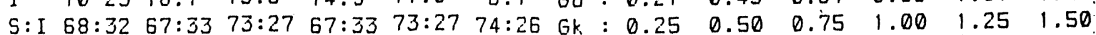

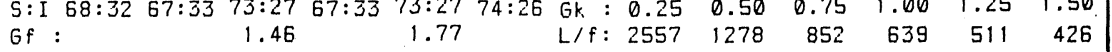

mecánicas en el extremo $y$ en el centro del vano:

$$
\begin{aligned}
& \omega_{\text {sd }^{1}}{ }^{1, \text { sup }} \omega_{\text {sd }^{0, \text { sup }}} \\
& \omega_{\text {sd }^{1}} \text {, inf } \omega_{\text {sd }} 0 \text {, inf }
\end{aligned}
$$

$\mu_{r d} \quad: M_{r d} / b h^{2} f_{c d}$

$: M_{u d} / b h^{2} f_{c d}$

: $M_{r k} / b h^{2} f_{c k}$

$: M_{\mathrm{uk}} / \mathrm{bh}^{2} \mathrm{f}_{\mathrm{ck}}$

momentos resistentes y solicitantes en el instarte de la rotura, para los estados límite de cálculc y utilización respectivamente

: $M_{k} / b h^{2} f_{c k}$

momentos solicitantes en la situación de servicio

En la tabla se dan en columna los momentos extremos y del vano:

$\mu_{1}$

Ho

$: q_{u d} / q_{k}$

: $q_{\mathrm{uk}} / q_{\mathrm{k}}$

coeficiente de seguridad y coeficiente de seguridad "característico: se dan $\in n$ la fila $\gamma_{f}$, debajo de los: momentos de rotura corres pondientes.

: carga de rotura en cálcuio : carga de rotura en servicio carga característica

: giro en el extremo de unc viga apoyada idêntica a la empotrada correspondient $\epsilon$, con cargà igual $q_{k} \cdot \gamma_{f} y$ momentos aplicados en los extremos de valor $M_{r d} 1$

: igual, siendo ahora en estado límite de utilización

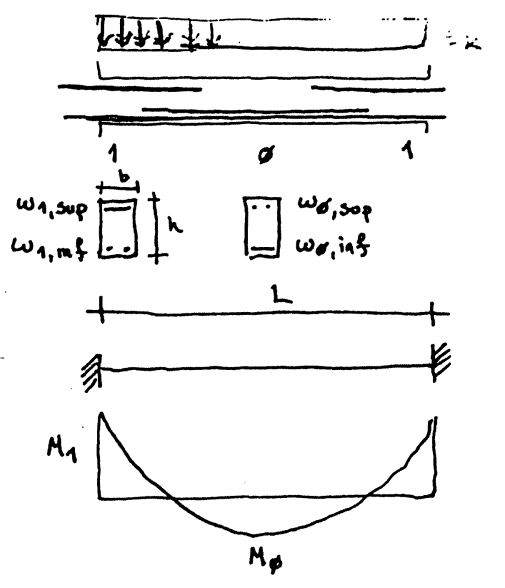



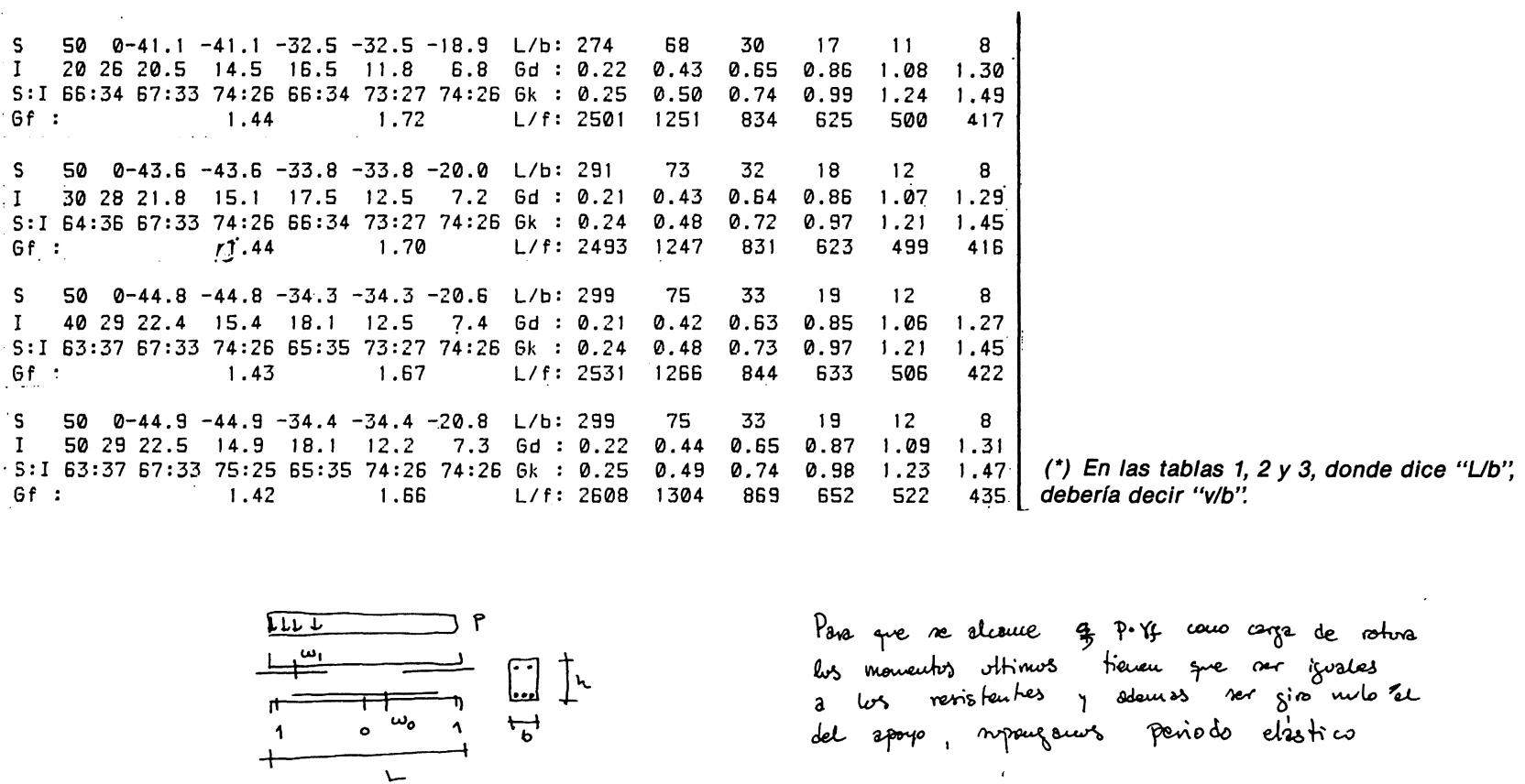

Si eseojemos $h_{1} w_{1}$ hay que colcular $b, w_{0}$. Momentos para ese cálculo:

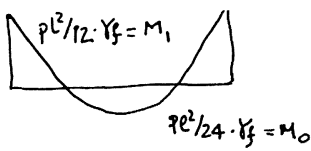

determinacion de b.

$$
M_{\text {rd } 1}=\alpha\left(w_{1}\right) \cdot b h^{2} f_{C d}=r_{f} \cdot \frac{p l^{2}}{12} \Rightarrow b=\frac{\gamma_{f} \cdot \frac{p e^{2}}{12}}{\alpha\left(w_{n}\right) \cdot h^{2} f_{d d}}
$$

DETERminacion de $\omega_{0}$

$$
M_{r d_{0}}=\alpha\left(\omega_{0}\right) \cdot b h^{2} f_{e d}=\gamma f \cdot \frac{p e^{2}}{24} \Rightarrow \text { ?? }
$$

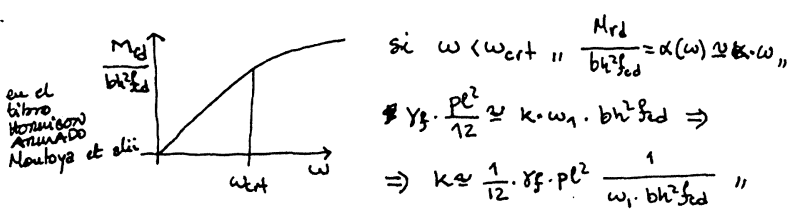

$$
\begin{aligned}
& M_{r d_{\phi}} \cong k \cdot \omega_{0} \cdot b h^{2} f_{c d}=\gamma f \cdot \frac{p e^{2}}{24} \Rightarrow
\end{aligned}
$$

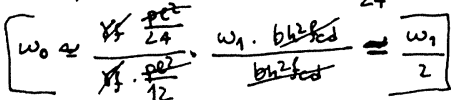

Fig. 7.-CALCULO APROXIMADO DE LA RELACION ENTRE LA CARGA DE DISEÑO Y LA MAXIMA CARGA COMPATIBLE.

\section{Al señor $\mathrm{K}$ la cabian varias opciones:}

A) abordar un análisis realista (ecuaciones constitutivas complejas, análisis cuando menos bidimensional y no-lineal, etcétera);

B) determinar el esquema de momentos de empotra-

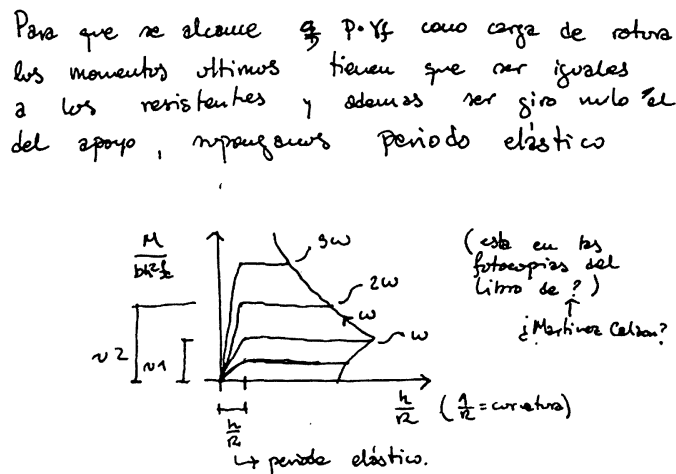

$$
\begin{aligned}
& \text { esto quiere deuir ge cri } b h^{2} f_{e d} \text { es constante }
\end{aligned}
$$

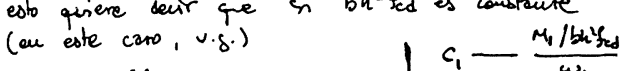

$$
\begin{aligned}
& c \triangleq \frac{M}{\omega}=\frac{2 M}{2 \omega}=\frac{3 M}{3 \omega} \cdot=\ldots\left\{\begin{array}{l}
C_{1}-\frac{M}{\omega_{1}} \\
c_{2}-\frac{M_{2} / b k^{2} k_{d}}{\omega_{2}}
\end{array}\right. \\
& y \text { en jeverd } \\
& c \simeq: \frac{M_{1} / b h^{2} f_{c}}{\omega_{1}}=\frac{s\left(M_{2} / b h^{2} f_{c}\right)}{\omega_{2}}=\ldots \\
& \text { en mesto cosso } \\
& \frac{M_{u d 1}}{\omega_{1}} \simeq \frac{M_{0 d 0}}{\omega_{0}} \cong c_{1} \cong c_{0} \simeq c
\end{aligned}
$$

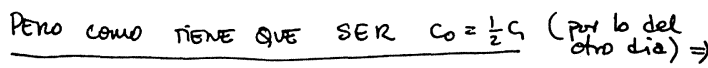

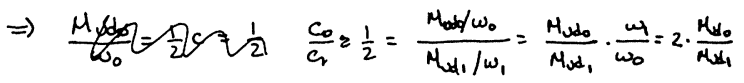

$$
\begin{aligned}
& \Rightarrow \text { Mud } \simeq \frac{1}{4} \text { Much « } \frac{1}{2} \text { Mudn !!! }
\end{aligned}
$$

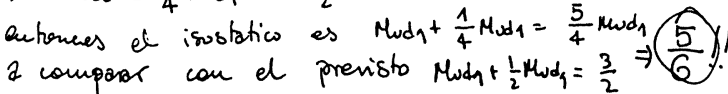

miento perfecto para el modelo parábola-rectángulo y armar las vigas con ese esquema;

C) introducir mejoras en el modelo unidimensional (momento-curvatura) que, sin complicarlo excesivamente, mejorará sus predicciones. "¡Mañana habrá que tomar drásticas decisiones!" 


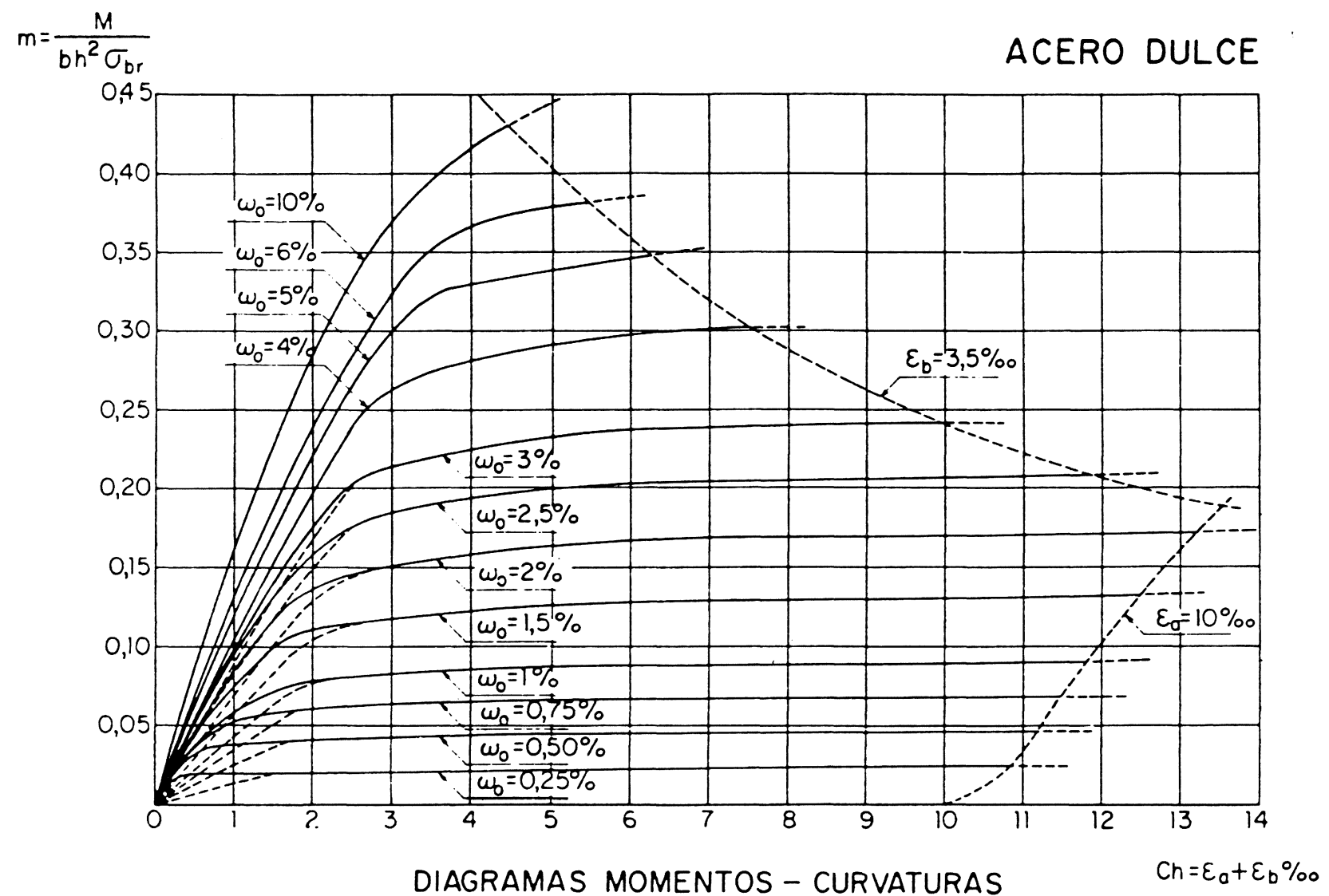

Fig. 8.-DIAGRAMAS MOMENTO-CURVATURA SEGUN LA CUANTIA GEOMETRICA: Se trata del gráfico al que parece referirse el señor K en su manuscrito (Fig. 7). Por despiste lo interpreta como si los diagramas se dieran en función de las cuantías mecánicas. Afortunadamente, a lo largo de su razonamiento, el cociente $f_{y d} / f_{c d}$ permanece constante: su equivocación en nada afecta a sus conclusiones (J. MARTINEZ CALZON, Comportamiento y cálculo anelástico de las estructuras hiperestáticas de hormigón armado y pretensado, Madrid, 1972).

\section{SEGUNDA SEMANA: MIERCOLES}

Si bien la alternativa A era el camino más seguro para llegar a alguna parte, era el más lento y el de mayor coste, "iy mi primo no es de los que esperan eternamente!". La alternativa $B$, en todo caso, no sería trabajo en balde. Puesto que la relación entre el momento de extremo y el del vano, para un material elástico, era -2/1 y conducía a esquemas de rotura con la proporción -3/1, convendría probar vigas armadas para resistir momentos en relación $-3 / 1,-4 / 1$ y así sucesivamente. Mientras el programa se ocupaba de obtener resultados, el señor $\mathrm{K}$ se dedicó a pensar acerca de las posibilidades que le ofrecia la alternativa $\mathrm{C}$.

"¿Qué es lo que el modelo unidimensional no representa y es fundamental?", se preguntaba. "La diferencia entre la viga apoyada y la empotrada sólo era de condiciones de apoyo, de condiciones de contorno... El giro ha de ser nulo... Y luego está la deformación por cortante que no hacía falta tener en cuenta..." Releyendo textos topa con el cálculo plástico en acero, donde no se dan este tipo de problemas: roturas plásticas, giros grandes en los apoyos, etc. "¿¡Giros grandes con momento constante!? ¿iGrandes deformaciones antes de la rotura!? ¿No limita, precisamente, el criterio de rotura de la sección de hormigón armado estas deformaciones a valores pequeños comparados con los del acero laminado? En esencia, se intenta transportar un método para materiales muy dúctiles a uno que no está claro que lo sea, y, naturalmente, el método fracasa. Con todo, si hasta ahora el modelo no ha dado problemas, debe existir otra fuente de ductilidad en este caso: ¿el cortante?"

Mientras tanto el programa imprimía resultados: la carga de rotura es la prevista si el esquema de armado re. siste momentos en proporción -5/1; proporción muy alejada de los habituales esquemas de armado (tabla 4). "Sigo donde estaba, y ¿dónde estaba?: el esfuerzo cortante... tensiones tangenciales... Hmmm..." Por fortuna para su salud, el sueño ganó la batalla una vez más. 
Tabla 4. COEFICIENTES DE SEGURIDAD EN VIGAS EMPOTRADAS CON APOYOS DE LONGITUD NULA: En función de las cuantías mecánicas de la sección más armada y de la proporción de momentos usados para el cálculo de las armaduras. En la última columna, se dan los mismos valores para una viga apoyada análoga.

\begin{tabular}{|c|c|c|c|c|c|c|}
\hline Wsd. & & $\begin{array}{l}\operatorname{Mrd1} / \mathrm{N} \\
67: 33\end{array}$ & $\begin{array}{l}r d 0 \\
75: 25\end{array}$ & $80: 20$ & $83: 17$ & $0: 100$ \\
\hline $\begin{array}{r}10 \\
0\end{array}$ & $\begin{array}{l}\text { Gfd: } \\
\text { Gfk: }\end{array}$ & $\begin{array}{l}1.47 \\
1.70\end{array}$ & $\begin{array}{l}1.57 \\
1.81\end{array}$ & $\begin{array}{l}1.60 \\
1.86\end{array}$ & $\begin{array}{l}1.60 \\
1.86\end{array}$ & $\begin{array}{l}1.60 \\
1.86\end{array}$ \\
\hline $\begin{array}{l}10 \\
10\end{array}$ & $\begin{array}{l}\text { Gfd: } \\
\text { Gfk: }\end{array}$ & $\begin{array}{l}1.46 \\
1.68\end{array}$ & & & & $\begin{array}{l}1.60 \\
1.84\end{array}$ \\
\hline $\begin{array}{r}20 \\
0\end{array}$ & $\begin{array}{l}\text { Gfd: } \\
\text { Gfk: }\end{array}$ & $\begin{array}{l}1.47 \\
1.73\end{array}$ & $\begin{array}{l}1.57 \\
1.86\end{array}$ & $\begin{array}{l}1.59 \\
1.89\end{array}$ & $\begin{array}{l}1.60 \\
1.89\end{array}$ & $\begin{array}{l}1.60 \\
1.90\end{array}$ \\
\hline $\begin{array}{l}20 \\
10\end{array}$ & $\begin{array}{l}\text { Gfd: } \\
\text { Gfk: }\end{array}$ & $\begin{array}{l}1.47 \\
1.68\end{array}$ & $\begin{array}{l}1.57 \\
1.80\end{array}$ & $\begin{array}{l}1.59 \\
1.84\end{array}$ & & $\begin{array}{l}1.60 \\
1.84\end{array}$ \\
\hline $\begin{array}{l}20 \\
20\end{array}$ & $\begin{array}{l}\text { Gfd: } \\
\text { Gfk: }\end{array}$ & $\begin{array}{l}1.45 \\
1.67\end{array}$ & & & & $\begin{array}{l}1.60 \\
1.84\end{array}$ \\
\hline $\begin{array}{r}30 \\
0\end{array}$ & $\begin{array}{l}\text { Gfk: } \\
\text { Gfd: }\end{array}$ & $\begin{array}{l}1.47 \\
1.77\end{array}$ & $\begin{array}{l}1.58 \\
1.89\end{array}$ & $\begin{array}{l}1.59 \\
1.92\end{array}$ & $\begin{array}{l}1.60 \\
1.93\end{array}$ & $\begin{array}{l}1.60 \\
1.94\end{array}$ \\
\hline $\begin{array}{l}30 \\
10\end{array}$ & $\begin{array}{l}\text { Gfk: } \\
\text { Gfd: }\end{array}$ & $\begin{array}{l}1.46 \\
1.72\end{array}$ & & $\begin{array}{l}1.59 \\
1.87\end{array}$ & & $\begin{array}{l}1.60 \\
1.88\end{array}$ \\
\hline $\begin{array}{l}30 \\
20\end{array}$ & $\begin{array}{l}\text { Gfd: } \\
\text { Gfk: }\end{array}$ & $\begin{array}{l}1.46 \\
1.68\end{array}$ & $\begin{array}{l}1.56 \\
1.79\end{array}$ & $\begin{array}{l}1.59 \\
1.83\end{array}$ & & $\begin{array}{l}1.60 \\
1.84\end{array}$ \\
\hline $\begin{array}{l}30 \\
30\end{array}$ & $\begin{array}{l}\text { Gfd: } \\
\text { Gfk: }\end{array}$ & $\begin{array}{l}1.44 \\
1.67\end{array}$ & & & & $\begin{array}{l}1.60 \\
1.84\end{array}$ \\
\hline $\begin{array}{r}40 \\
0\end{array}$ & $\begin{array}{l}\text { Gfk: } \\
\text { Gfd: }\end{array}$ & $\begin{array}{l}1.47 \\
1.81\end{array}$ & $\begin{array}{l}1.58 \\
1.94\end{array}$ & $\begin{array}{l}1.60 \\
1.96\end{array}$ & $\begin{array}{l}1.60 \\
1.96\end{array}$ & $\begin{array}{l}1.60 \\
1.99\end{array}$ \\
\hline $\begin{array}{l}40 \\
10\end{array}$ & $\begin{array}{l}\text { Gfk: } \\
\text { Gfd: }\end{array}$ & $\begin{array}{l}1.45 \\
1.74\end{array}$ & & $\begin{array}{l}1.59 \\
1.90\end{array}$ & & $\begin{array}{l}1.60 \\
1.91\end{array}$ \\
\hline $\begin{array}{l}40 \\
20\end{array}$ & $\begin{array}{l}\text { Gfk: } \\
\text { Gfd: }\end{array}$ & $\begin{array}{l}1.45 \\
1.71\end{array}$ & & $\begin{array}{l}1.59 \\
1.86\end{array}$ & & $\begin{array}{l}1.60 \\
1.87\end{array}$ \\
\hline $\begin{array}{l}40 \\
30\end{array}$ & $\begin{array}{l}\text { Gfd: } \\
\text { Gfk: }\end{array}$ & $\begin{array}{l}1.44 \\
1.68\end{array}$ & $\begin{array}{l}1.54 \\
1.78\end{array}$ & $\begin{array}{l}1.59 \\
1.83\end{array}$ & & $\begin{array}{l}1.60 \\
1.84\end{array}$ \\
\hline $\begin{array}{l}40 \\
40\end{array}$ & $\begin{array}{l}\text { Gfd: } \\
\text { Gfk: }\end{array}$ & $\begin{array}{l}1.43 \\
1.66\end{array}$ & & & & $\begin{array}{l}1.60 \\
1.84\end{array}$ \\
\hline $\begin{array}{r}50 \\
0\end{array}$ & $\begin{array}{l}\text { Gfd: } \\
\text { Gfk: }\end{array}$ & $\begin{array}{l}1.47 \\
1.95\end{array}$ & $\begin{array}{l}1.58 \\
2.07\end{array}$ & $\begin{array}{l}1.59 \\
2.09\end{array}$ & $\begin{array}{l}1.60 \\
2.05\end{array}$ & $\begin{array}{l}1.60 \\
2.15\end{array}$ \\
\hline $\begin{array}{l}50 \\
10\end{array}$ & $\begin{array}{l}\text { Gfd: } \\
\text { Gfk: }\end{array}$ & $\begin{array}{l}1.46 \\
1.77\end{array}$ & & $\begin{array}{l}1.59 \\
1.93\end{array}$ & & $\begin{array}{l}1.60 \\
1.95\end{array}$ \\
\hline $\begin{array}{l}50 \\
20\end{array}$ & $\begin{array}{l}\text { Gfd: } \\
\text { Gfk: }\end{array}$ & $\begin{array}{l}1.44 \\
1.72\end{array}$ & & $\begin{array}{l}1.59 \\
1.88\end{array}$ & & $\begin{array}{l}1.60 \\
1.90\end{array}$ \\
\hline $\begin{array}{l}50 \\
30\end{array}$ & $\begin{array}{l}\text { Gfd: } \\
\text { Gfk: }\end{array}$ & $\begin{array}{l}1.43 \\
1.69\end{array}$ & & $\begin{array}{l}1.59 \\
1.86\end{array}$ & & $\begin{array}{l}1.60 \\
1.86\end{array}$ \\
\hline $\begin{array}{l}50 \\
40\end{array}$ & $\begin{array}{l}\text { Gfd: } \\
\text { Gfk: }\end{array}$ & $\begin{array}{l}1.43 \\
1.66\end{array}$ & $\begin{array}{l}1.54 \\
1.78\end{array}$ & $\begin{array}{l}1.59 \\
1.83\end{array}$ & & $\begin{array}{l}1.60 \\
1.84\end{array}$ \\
\hline 50 & $\begin{array}{l}\text { Gfd: } \\
\text { Gfk: }\end{array}$ & & & & & $\begin{array}{l}1.60 \\
1.84\end{array}$ \\
\hline
\end{tabular}

\section{SEGUNDA SEMANA: JUEVES}

"Pero, iiclaro!!: no sólo el giro ha de ser nulo en la sección del apoyo, también el cortante, y nuestra gráfica de cortantes es discontinua precisamente en ese punto. El apoyo, por tanto, no puede ser de longitud nula (puntual), y si el apoyo es finito, la gráfica de momentos deja de ser cóncava para hacerce convexa y... Veamos, si el apoyo fuera de hormigón, su área tendría que ser tal que las tensiones no superarán, $f_{c}$, o si estuviera muy armado, $2 f_{c}$, como mucho; y si tiene el mismo ancho que la viga, su canto viene dado y su proporción a la luz (a/L) será la razón compuesta $\left(q / 2 f_{c}\right) \times(V / b)$..." (Fig. 9).

El señor K programó el ordenador bajo esta nueva hipótesis y se sentó de nuevo a esperar. Como ahora la dimensión del apoyo variaba con la razón L/h, los cálculos integrales se multiplicaban por el número de esbelteces que quisiera probar. La espera sería larga.

Su cabeza seguía dando vueltas: Bajo la nueva hipótesis las vigas se armaban para momentos que en el apoyo no serían nunca alcanzados, esto podia explicar que el burdo método de la norma funcionará en la práctica. Con todo, incluso si la nueva hipótesis funcionaba ¿que ocurría en ese trozo de pieza a lo largo del cual

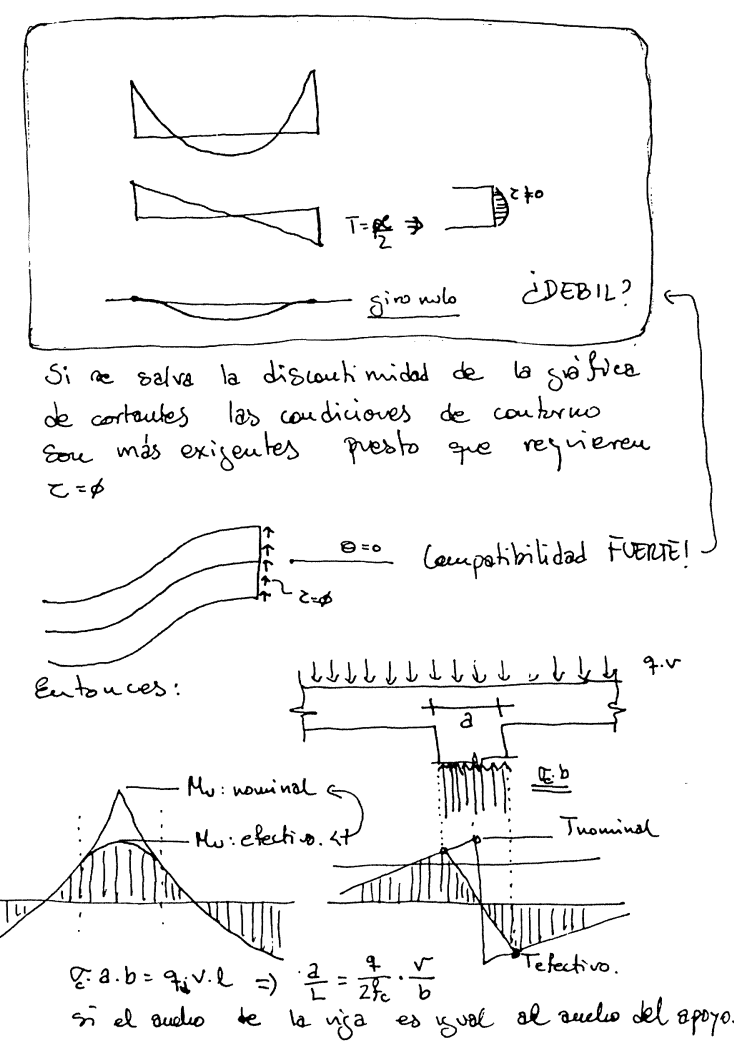

Fig. 9.-COMPATIBILIDAD FUERTE: UN MODELO DE APOYO DE AN CHO FINITO: Se presupone que la variación de tensiones normales en todo el ancho del apoyo es nula; entonces, por simple aplicación de las ecuaciones de equilibrio, se puede determinar el momento flec. tor en cualquier sección. 
las tensiones tangenciales se anulaban? Si el soporte era de hormigón el cortante disminuía a lo largo de su canto hasta anularse en el eje, pero ¿si fuera otro apoyo? Y, en este caso, ¿de qué tipo? Como científico cualificado, el señor $\mathrm{K}$ se dedicó a falsear su hípótesis. La noche le sorprendió con la mesa repleta de una jugosa colección de dibujos de apoyos de vigas, a cada cual más disparatado... "Mañana, será otro día", pensó resignadamente el señor $\mathrm{K}$.

\section{SEGUNDA SEMANA: VIERNES}

A la mañana siguiente, el señor $K$ pudo ver los primeros resultados de la nueva hipótesis: para unos momentos de diseño en relación $2 / 1$, seguía sin alcanzarse la carga de rotura teórica, si bien en algunos casos la carga de rotura alcanzada estaba bastante próxima (tabla 5). Sin embargo, aún cuando se hubieran alcanzado los valores previstos no hubiera quedado satisfecho: pues,

Tabla 5. VIGAS DOBLEMENTE EMPOTRADAS SIMETRICAS. CARGAS COMPATIBLES. APOYOS DE LONGITUD FINITA $\left(\sigma_{\mathrm{c}}=2 \mathrm{f}_{\mathrm{cd}}\right)$.

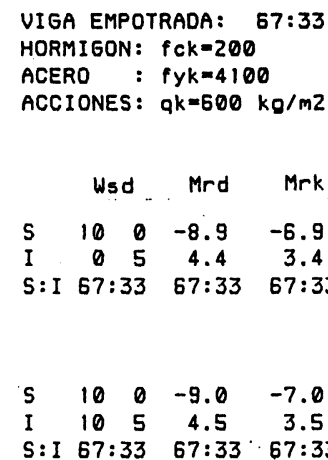

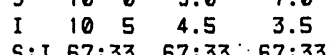

S $\quad 20 \quad 0-16.6-13.1$

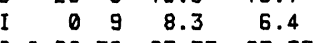

S:I $68: 32 \quad 67: 33 \quad 67: 33$

S $\quad 20 \quad 0-17.8 \div-13.7$

I $\quad \begin{array}{llll}10 & 10 & 8.9 & 6.9\end{array}$

S:I $67: 33 \quad 67: 33 \quad 66: 34$

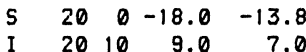

S:I $66: 34 \quad 67: 33 \quad 66: 34$

$5 \quad 30 \quad 0 \quad-23.1 \quad-18.7$

$\begin{array}{lllll} & 0 & 13 & 11.5 & 9.0\end{array}$

S:I 69:31 67:33 67:33

a $\quad 30 \quad 0 \quad-25.6 \quad-20.0$

$\begin{array}{llll}10 & 15 & 12.8 & 10.0\end{array}$

$\begin{array}{lll}\text { s:I } 67: 33 & 67: 33 & 67: 33\end{array}$

C $\quad 3 a \quad \theta-25.8-20.5$ T $29 \begin{array}{llll}16 & 13.4 & 10.5\end{array}$ s:J $66: 34 \quad 67: 33 \quad 66: 34$

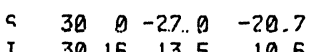

$\begin{array}{lllll}\text { T } & 39 & 16 & 13.5 & 10.6\end{array}$

S:I $66: 34 \quad 67: 33 \quad 66: 34$

$\begin{array}{llllll}5 & 40 & 0 & -28.3 & -2.3 .4\end{array}$

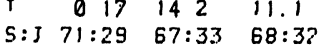

Gc=1.5 modelo: Parabola-Rectangulo $G s=1.15$ modelo: $A E H-N$

$G f=1.6$ $\begin{array}{lrrrrrrr}\text { L/h } & \because & 5 & 10 & 15 & 20 & 25 & 30 \\ \text { U/b } & : & 59 & 15 & 7 & 4 & 2 & 2 \\ \text { (Ml/MO)d: } & 72: 28 & 72: 28 & 73: 27 & 72: 28 & 73: 27 & 73: 27 \\ \text { Gfd } & : & 1.50 & 1.48 & 1.47 & 1.47 & 1.47 & 1.47 \\ \text { (Ml/MO)k: } & 72: 28 & 73: 27 & 73: 27 & 73: 27 & 73: 27 & 73: 27 \\ \text { Gfk } & : & 1.74 & 1.71 & 1.71 & 1.70 & 1.70 & 1.70\end{array}$

$\begin{array}{cccccccc}\text { U/b } & : & 60 & 15 & 7 & 4 & 2 & 2 \\ \text { (MI/MO)d: } & 72: 28 & 73: 27 & 73: 27 & 73: 27 & 73: 27 & 73: 27\end{array}$ $\begin{array}{llllllll}\text { Gfd } & : & 1.50 & 1.47 & 1.46 & 1.46 & 1.46 & 1.46\end{array}$ (Ml/MO)k: $72: 28 \quad 73: 27 \quad 73: 27 \quad 73: 27 \quad 73: 27 \quad 73: 27$ $\begin{array}{llllllll}\text { Gfk } & : & 1.72 & 1.69 & 1.69 & 1.68 & 1.68 & 1.68\end{array}$ $\begin{array}{ccccccc}\text { U/b }: 111 & 28 & 12 & 7 & 4 & 3 \\ \text { (MI/MO): } & 72: 28 & 72: 28 & 72: 28 & 73: 27 & 73: 27 & 73: 27\end{array}$ $\begin{array}{lllllllll}\text { Gfd }: & : & 1.53 & 1.49 & 1.48 & 1.47 & 1.47 & 1.47\end{array}$ (MI/MO)K: $72: 28 \quad 73: 27 \quad 73: 27 \quad 73: 27 \quad 73: 27 \quad 73: 27$ $\begin{array}{llllllll}\text { Gfk } & : & 1.81 & 1.76 & 1.74 & 1.74 & 1.74 & 1.74\end{array}$ $\begin{array}{lccccccc}\text { U/b } & 119 & 30 & 13 & 7 & 5 & 3 \\ \text { (MI/MO }: & 72: 28 & 72: 28 & 73: 27 & 73: 27 & 73: 27 & 73: 27\end{array}$

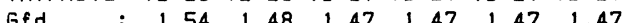

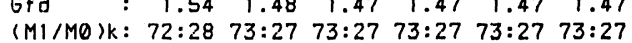

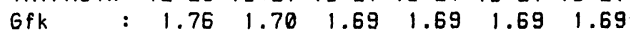
$\begin{array}{llllllll}U / 6 & 120 & 30 & 13 & 7 & 5 & 3\end{array}$ $\begin{array}{lrrrrrr}\text { (MI/MO)d: } & 72: 28 & 73: 27 & 73: 27 & 73: 27 & 74: 26 & 74: 26 \\ \text { Gfd }: & 1.52 & 1.47 & 1.46 & 1.45 & 1.45 & 1.45\end{array}$ $\begin{array}{lrrrrrrr}\text { Gfd } & : & 1.52 & 1.47 & 1.46 & 1.45 & 1.45 & 1.45 \\ \text { (M1/MO)k: } & 72: 28 & 73: 27 & 73: 27 & 73: 27 & 73: 27 & 73: 27\end{array}$

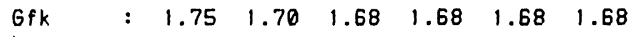
$\begin{array}{llllllll}U / b & : & 154 & 38 & 17 & 10 & 6 & 4\end{array}$ (MI/MO)d: $72: 28 \quad 72: 28 \quad 73: 27 \quad 73: 27 \quad 73: 27 \quad 73: 27$ $\begin{array}{llllllll}\text { Gfd } & : & 1.54 & 1.49 & 1.48 & 1.47 & 1.47 & 1.47\end{array}$ (MI/MO)k: $72: 28 \quad 73: 27 \quad 73: 27 \quad 73: 27 \quad 73: 27 \quad 73: 27$ $\begin{array}{llllllll}\text { Gfk } & : & 1.86 & 1.79 & 1.78 & 1.77 & 1.77 & 1.77\end{array}$

$\begin{array}{llllllll}\text { W/b } & : & 171 & 43 & 19 & 11 & 7 & 5\end{array}$ (MI/MO)d: $72: 28 \quad 73: 27 \quad 73: 27 \quad 73: 27 \quad 73: 27 \quad 73: 27$ $\begin{array}{llllllll}.6 \mathrm{fd} & : & 1.54 & 1.48 & 1.47 & 1.46 & 1.46 & 1.46\end{array}$ $\begin{array}{lllllll}(M I / M O) k: & 72: 28 & 72: 28 & 73: 27 & 73: 27 & 73: 27 & 73: 27\end{array}$ $\begin{array}{llllllll}\text { Gfk } & : & 1.83 & 1.75 & 1.73 & 1.73 & 1.72 & 1.72\end{array}$

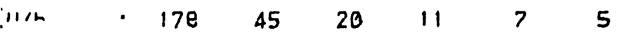

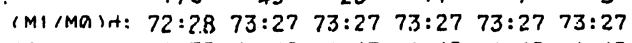
$\begin{array}{llllllll}\text { Gf } & \therefore & 1.56 & 1.48 & 1.47 & 1.46 & 1.46 & 1.46\end{array}$

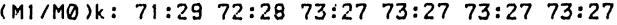
$\begin{array}{lllllllll}.6 \mathrm{fk} & : & 1.79 & 1.71 & 1.70 & 1.69 & 1.69 & 1.68\end{array}$

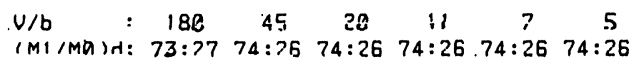
$\begin{array}{llllllll}\text { Gfd } & : & 1.53 & 1.46 & 1.45 & 1.45 & 1.44 & 1.44\end{array}$ (M)/MO)k: $72: 28 \quad 73: 27 \quad 73: 27 \quad 73: 27 \quad 73: 27 \quad 73: 27$ $\begin{array}{llllllll}G \mathrm{fk} & : & 1.78 & 1.70 & 1.68 & 1.68 & 1.67 & 1.67\end{array}$ $\begin{array}{llllllll}\mathrm{V} / \mathrm{h} & : & 188 & 47 & 21 & 12 & 8 & 5\end{array}$ $\begin{array}{llllll}\text { (MI/MO)d: } 72: 28 & 72: 28 & 72: 28 & 72: 28 & 72: 28 & 72: 28\end{array}$ $\begin{array}{lllllllll}\text { Gfd } & : & 1.55 & 1.49 & 1.48 & 1.48 & 1.48 & 1.48\end{array}$ $\begin{array}{llllll}(M 1 / M O) k: 73: 27 & 73: 27 & 73: 27 & 73: 27 & 73: 27 & 73: 27\end{array}$

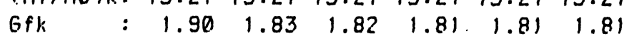

Le relaciour artre los momentos nominales (aquellos que teudria la misma riga cuendo el epoyo as nulo) $t$ los electivas ser's

$$
\begin{aligned}
& \mu_{e}=\left\{\begin{array}{c}
\mu_{n}\left(\frac{2}{2 L}\right)+\left\{\left(\frac{x}{L}\right)^{2}-\left(\frac{d}{2 L}\right)^{2}\right\} \approx\left\{\frac{L}{2}-1\right\} \times 4 \mu_{n i} \\
\text { si } x<\frac{2}{2} \\
\mu_{n}(x) \text { si } x \geqslant \frac{2}{2}
\end{array}\right. \\
& \text { siendo tee : momacto efectivo }
\end{aligned}
$$

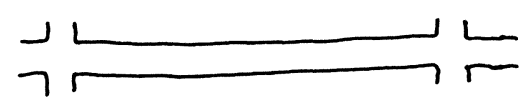


$\begin{array}{lllll}5 & 40 & 0 & -32: 1 & -25.6\end{array}$ $\begin{array}{lllll}1 & 10 & 19 & 16.0 & 127 \\ \text { s: I } & 68: 32 & 67: 33 & 57: 33\end{array}$

$\begin{array}{rrrrr}5 & 40 & 0 & -34.6 & -26.8 \\ 1 & 20 & 21 & 173 & 137\end{array}$ $5: J \quad 65: 34 \quad 67: 33$ 65:34

$\begin{array}{llllll}5 & 49 & 0 & -35.8 & -27.4\end{array}$ S:I $65: 35 \quad 67: 33 \quad 66: 34$

s. $40 \quad 0-35.9 \quad-275$ I. $4022.18 .0 \quad 14.3$ S:I $65: 35 \quad 67: 33 \quad 66: 34$

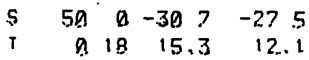
s: $1 \quad 73: 27 \quad 67: 3.3 \quad 69: 3$

$5 \quad 50 \quad 0 \quad-37.3 \quad-30.3$ I $\begin{array}{llll}10 & 23 & 18.7 & 14.9\end{array}$ S:I $68: 32 \quad 67: 33 \quad 67: 33$

$\begin{array}{lrrrr}\text { S } & 50 & 0 & -41.1 & -32.5 \\ \text { I } & 20 & 26 & 20.5 & 16.5\end{array}$ S: I $66: 34 \quad 67: 33 \quad 66: 34$

$\begin{array}{lllll}5 & 50 & 0 & -43.6 & -33.8\end{array}$ $\begin{array}{lllll}30 & 28 & 21.8 & 17.5\end{array}$ S:I $64: 36 \quad 67: 33 \quad 66: 34$

$\begin{array}{lllll}5 & 50 & 0 & -44.8 & -34.3\end{array}$ I $\begin{array}{llll}40 & 29 & 22.4 & 18.1\end{array}$ S:I $63: 37 \quad 67: 33 \quad 65: 35$

\begin{tabular}{|c|c|c|c|c|c|c|c|}
\hline$v / b$ & : & 214 & 53 & 24 & 13 & 9 & 6 \\
\hline$(M 1 / M O) d$ & & $73: 27$ & $73: 27$ & $73: 27$ & $73: 27$ & $73: 27$ & $73: 27$ \\
\hline Gf.J & : & 1.55 & 1.48 & $1 \ldots 47$ & 1.46 & 1.46 & 1.46 \\
\hline$(M 1 / M O) k$ & & $73: 27$ & $73: 27$ & $73: 27$ & $73: 27$ & $73: 27$ & $73: 27$ \\
\hline $6 \mathrm{fk}$ & : & 1.86 & 1.77 & 1.76 & 1.75 & 1.75 & 1.75 \\
\hline $1 / 6$ & $:$ & 231 & 58 & 26 & 14 & 8 & 6 \\
\hline$(M 1 / M O) d$ & & $73: 27$ & $73: 27$ & $73: 27$ & $24: 76$ & $74: 26$ & $74: ? 6$ \\
\hline Gf & : & 1.55 & 1.48 & 1.46 & 1,45 & $1 \ldots 45$ & 1.45 \\
\hline$(M \mid / M Q) k$ & & $72: 28$ & $72: 28$ & $73: 27$ & $73: 27$ & $73: 27$ & $73: 27$ \\
\hline Gfk & : & 1.85 & 1.75 & 1.73 & 1.72 & 1.7 .1 & 1.71 \\
\hline $4: b$ & $:$ & 239 & 60 & 27 & 1.5 & 10 & 7 \\
\hline$(M 1 / M a) A$ & & $72: 28$ & $73: 27$ & $74: 26$ & $74: 26$ & $74: 26$ & $74: 26$ \\
\hline Ged & : & 1.57 & 1.48 & 1.4 .6 & 1.4 .5 & 1.45 & 1.45 \\
\hline$(M 1 / M O) k$ & & $71: 29$ & $72: 28$ & $73: 27$ & $73: 27$ & $73: 27$ & $73: 27$ \\
\hline $6 \mathrm{fk}$ & : & 1.82 & 1.71 & 1.69 & 1.6 .9 & 1.68 & 1.68 \\
\hline $\mathrm{W} / \mathrm{h}$ & : & 2.40 & 50 & 37 & 15 & 10 & 7 \\
\hline$(M) / M O) d$ & & $73: 27$ & $74: 26$ & $74: 26$ & $74: 26$ & $74: 26$ & $75: 25$ \\
\hline Gfd & : & 1.55 & 1.46 & 1.44 & 1.44 & 1.44 & 1.4 .3 \\
\hline$(M) / M O) k$ & & $72: 28$ & $73: 27$ & $73: 27$ & $73: 27$ & $73: 27$ & $74: 26$ \\
\hline Gfk & $:$ & 1.81 & 1.70 & 1.68 & 1.67 & 1.67 & 1.67 \\
\hline$U / b$ & : & $2 \$ 4$ & 51 & 23 & 1.3 & 8 & $\varepsilon$ \\
\hline$(M 1 / M a) A$ & & $73: 27$ & $73: 2.7$ & $23: 27$ & $73: 27$ & $7.3: 27$ & $73: 27$ \\
\hline fifd & : & 1.55 & 1.49 & 1.47 & 1.47 & 1.47 & 1.47 \\
\hline$(M 1 / M Q) k$ & & $74: 26$ & $74: 26$ & $74: 25$ & $74: 26$ & $74: 26$ & $74: 26$ \\
\hline Gfk & : & 2.06 & 1.97 & 1.96 & 1.95 & 1.95 & 1.95 \\
\hline$V / b$ & : & 249 & 62 & 28 & 16 & 10 & 7 \\
\hline$(M 1 / M O) d$ & & $73: 27$ & $73: 27$ & $73: 27$ & $73: 27$ & $73: 27$ & $73: 27$ \\
\hline Gfd & : & 1.56 & 1.48 & 1.47 & 1.46 & 1.46 & 1.46 \\
\hline$(M I / M O) k$ & & $73: 27$ & $73: 27$ & $73: 27$ & $73: 27$ & $73: 27$ & $73: 27$ \\
\hline$G \mathrm{fk}$ & : & 1.90 & 1.80 & 1.79 & 1.78 & 1.78 & 1.78 \\
\hline$V / b$ & : & 274. & 68 & 30 & 17 & 11 & 8 \\
\hline$\langle M| / M O) d$ & & $73: 27$ & $74: 26$ & $74: 26$ & $74: 26$ & $74: 26$ & $74: 26$ \\
\hline Gfd & : & 1.56 & 1.47 & 1.46 & 1.45 & 1.45 & 1.45 \\
\hline$(M) / M O) k$ & & $73: 27$ & $73: 27$ & $73: 27$ & $73: 27$ & $73: 27$ & $73: 27$ \\
\hline $6 \mathrm{fk}$ & . & 1.87 & 1.76 & 1.74 & 1.74 & 1.73 & 1.73 \\
\hline$V / b$ & : & 291 & 73 & 32 & 18 & 12 & 8 \\
\hline$(M 1 / M O) d$ & & $73: 27$ & $74: 26$ & $74: 26$ & $74: 26$ & $74: 26$ & $74: 26$ \\
\hline Gfd & : & 1.57 & 1.47 & 1.45 & 1.45 & 1.44 & 1.44 \\
\hline$(M) / M O) k$ & & $72: 28$ & $72: 28$ & $73: 27$ & $73: 27$ & $73: 27$ & $73: 27$ \\
\hline$G f k$ & 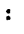 & 1.87 & 1.75 & 1.72 & 1.71 & 1.71 & 1.71 \\
\hline$U / b$ & : & 299 & 75 & 33 & 19 & 12 & 8 \\
\hline (M & & $73: 27$ & $74: 26$ & $74: 26$ & $74: 26$ & $74: 26$ & $74: 26$ \\
\hline Gfd & $:$ & 1.58 & 1.47 & 1.45 & 1.44 & 1.44 & 1.44 \\
\hline$(M 1 / M O) k$ & & $72: 28$ & $73: 27$ & $73: 27$ & $73: 27$ & $73: 27$ & $73: 27$ \\
\hline G fk. & $\theta^{\circ}$ & 1.84 & 1.72 & 1.69 & 1.68 & 1.68 & 1.68 \\
\hline
\end{tabular}

en efecto, con la nueva hipótesis los momentos máximos eran menores y nada impedía (en principio) armar las vigas con menores cuantías, y entonces la carga de rotura volvería a alejarse de la prevista más aún. Dicho de otro modo, puesto que con el modelo propuesto no se alcanzaba la carga de rotura prevista, se sobredimensionaban las armaduras hasta alcanzar ese valor. Lo cual, de cara a optimizar un diseño industrial, no parecía de recibo.

Una sensación de estar siendo víctima de una pesadiIla terminó por embargarle, a la que siguió cierta nostalgia. Abatido se dejo caer en el sillón recordando sus tiempos en la universidad y la claridad de aquellos días: Bacon, Galileo, Newton, Saint Venant, Navier... y tarıtos otros. "Un momento", pensó, “¿iSaint Venant!? ¿No fue él quien dijo: "Sólo podemos establecer satisfac. toriamente la deformación de las vigas si renunciamos a considerar sus extremos?n"
Presa de gran excitación reunió sobre la mesa sus dibujos de apoyos de dias anteriores y el viejo texto del maestro francés: "En primer lugar, dibujaré la viga completa; después si he de hacer caso de Saint Venant la quitaré dos trozos en ambos extremos de una longitud de un canto; ambos trozos habré de sustituirlos por una suerte de pieza que cumpla con las condiciones impuestas: si el apoyo es inferior (como normalmente ocurre), bastaría un triángulo de hormigón cuya hipotenusa una el apoyo con la fibra superior de la viga para anular las tensiones tangenciales en el apoyo, en la parte superior seguiria teniendo la armadura aunque ahora sola y al aire, a tensión y resultante constante; el momento sin embargo no será constante a lo largo de ese canto porque o bien la posición de la resultante del bloque de compresiones varía disminuyendo el brazo de palanca con el que actúan las tensiones de la barra de acero, o bien, si distinguimos entre la compresión inferior en el hormigón de la oblicua a lo largo de la hi- 
potenusa, la componente horizontal de ésta trabaja contra el momento de la armadura disminuyéndolo. Es lo mismo que ocurre en una viga metálica en celosía." (Figs. 10 y 11.)

Con su tradicional prudencia, el señor $K$ sabía que aquello no era más que una descripción bastante grosera de lo que en realidad ocurría, que era "sumar con los dedos". Sin embargo, su pieza tenía tantas analogías formales con las fisuras de las piezas rotas experimentalmente, con algunos de sus dibujos y con otros de piezas de hormigón (zapatas, ménsulas, etc.) que no duda que por alli puede llegar a alguna parte. "Claro, que ahora, hablar de curvatura en la pieza de unión no tiene sentido, habrá que calcular el giro directamente: por una parte, la tensión en la barra de acero es constante y su deformación también y de igual valor que la que corresponde al momento del extremo. De otra, el triángulo de hormigón sería complicado analizarlo con rigor. Supondré que su fibra inferior se deforma básicamente con deformaciones del orden de las que co-
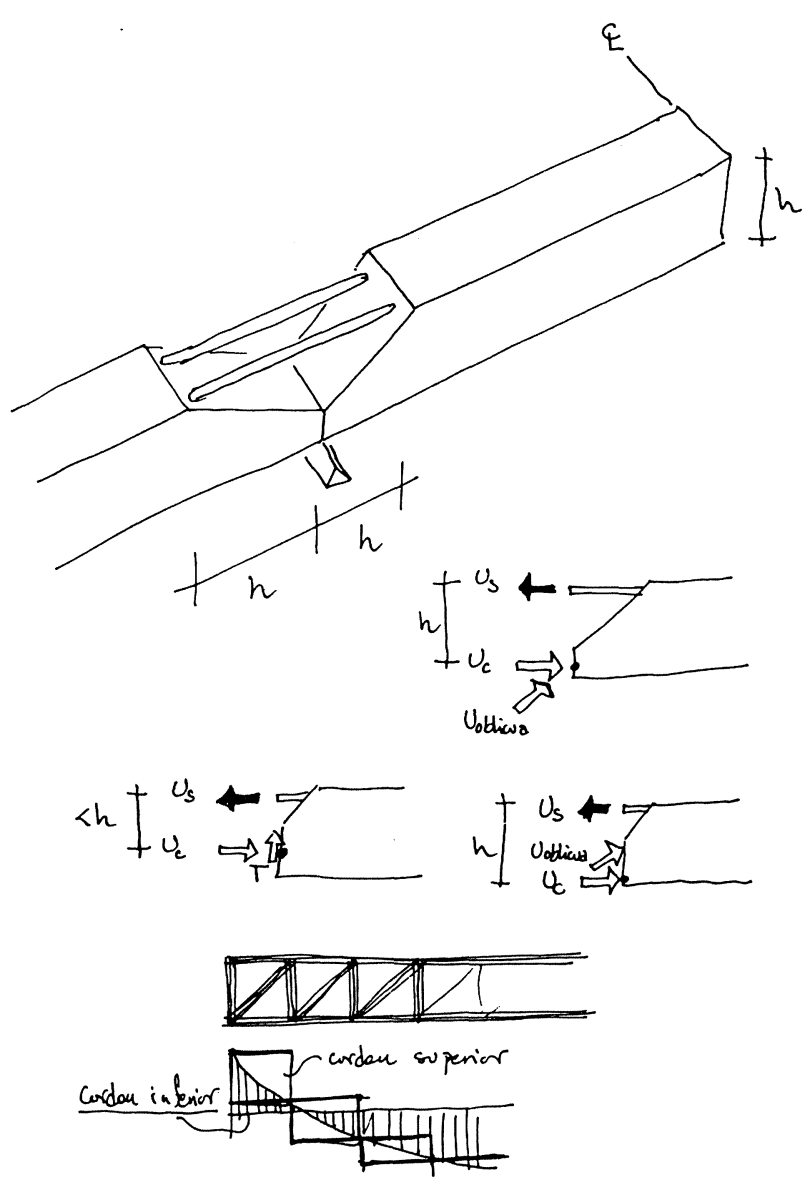

Fig. 10.-COMPATIBILIDAD FUERTE: UN MODELO DE APOYO EN CE LOSIA: Se consigue anular las tensiones tangenciales en el apoyo su primiendo, a efectos mecánicos, el triángulo superior de hormigón. Tal hipótesis es plausible en virtud del proceso de fisuración: ha de superarse el momento de fisuración de la pieza para aplicarla. Podría pensarse que también es necesaria la presencia de estribos: si el mo delo se aplica sólo al primer canto de la pieza, siempre hay un estribo: el apoyo. Se obvian así las complicaciones del apoyo finito.
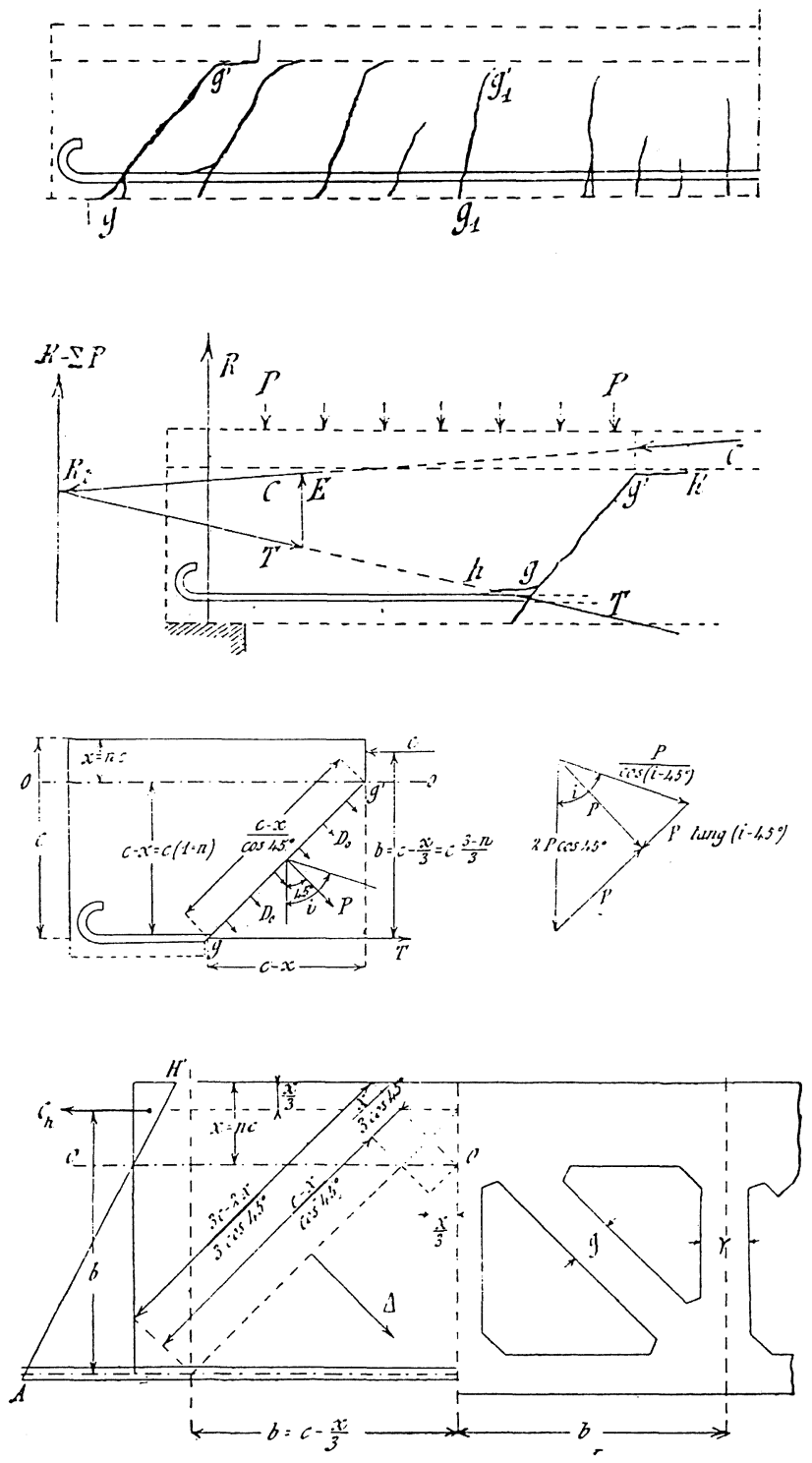

Fig. 11.-MODELOS CLASICOS: Obsérvese el esquema para el equilibrio entre fisuras, asi como la descripción de las bielas comprimidas de hormigón: desde finales del siglo pasado quedaron propuestos diversos modelos para un tratamiento más veraz del material. La caren cia de instrumentos adecuados de cálculo propició que se adoptarán los modelos "elásticos" (Juan Manuel de ZAFRA, Construcciones de Hormigón Armado, Madrid, 1911).

rresponden al momento a un canto del apoyo. También habrá acortamientos en la dirección de la hipotenusa, pero si no los tengo en cuenta ${ }^{2}$, el giro que asi obtenga será como mucho igual al máximo que el modelo pueda ofrecerme, y normalmente será menor, y como este giro es favorable para lograr cumplir las condiciones de compatibilidad, la aproximación puede considerarse prudente. ¡Ya veremos!" (Fig. 12.)

\footnotetext{
2 También habrá alargamientos en el cateto vertical, pero no contabilizándolos; lo que no se tiene en cuenta es, precisamente, la deformación por cortante. De este modo, el señor K era coherente, aún sin decirlo, con sus formulaciones anteriores: el cortante y las tensiones tangenciales vienen a cuento sólo en lo que toca al equilibrio (tabla 6).
} 

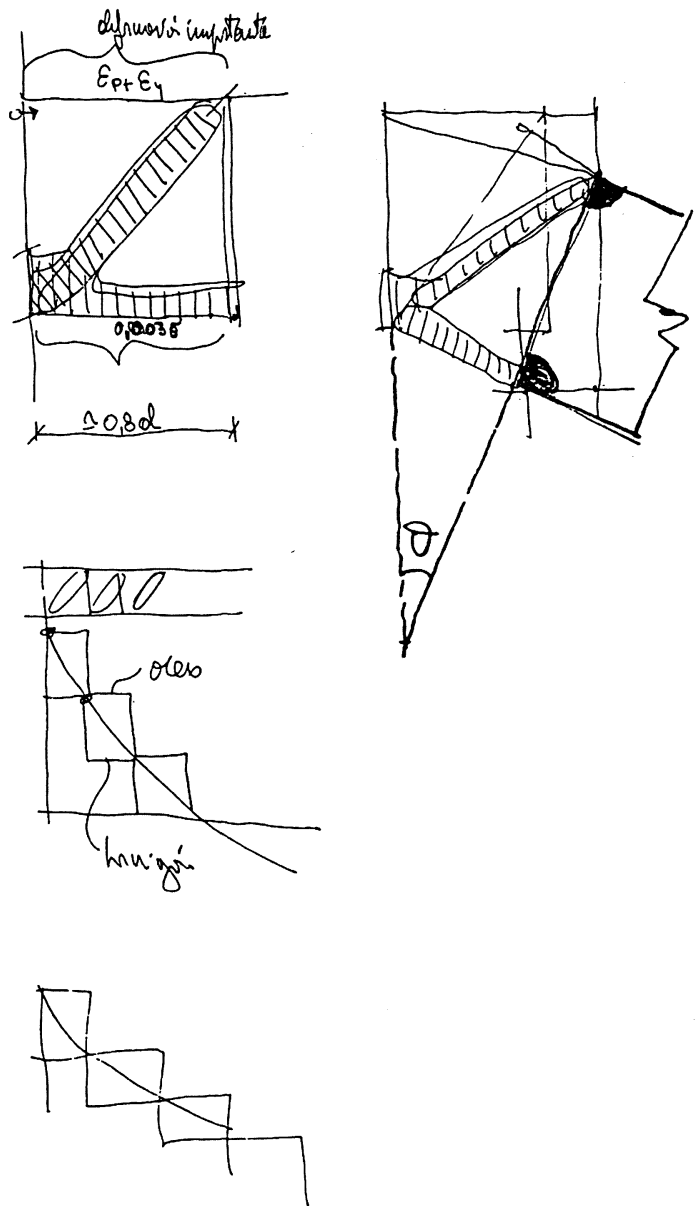

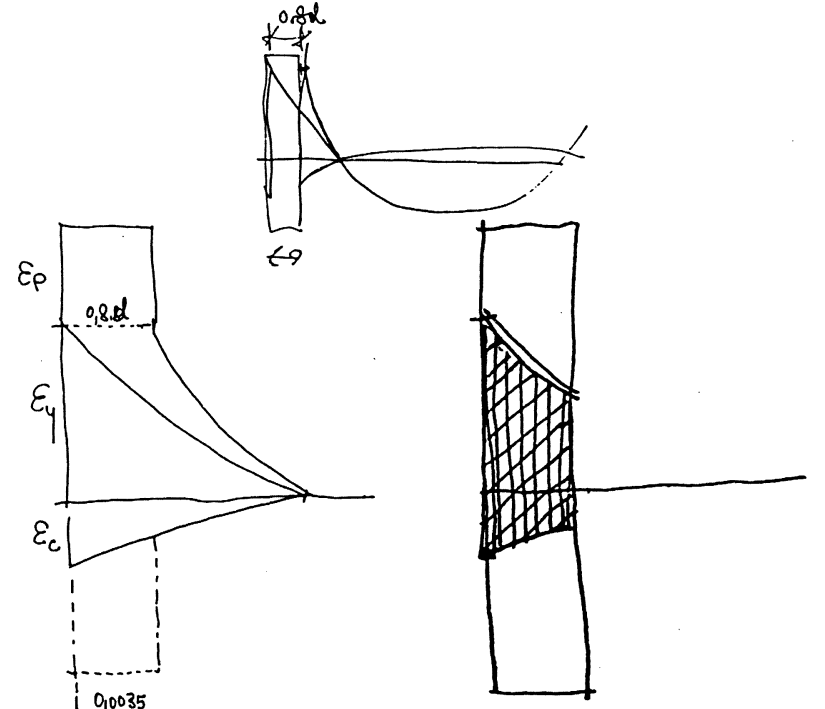

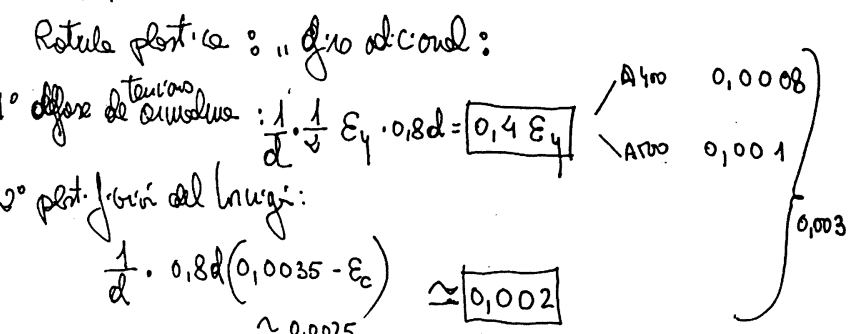
$3^{\circ}$ pent. for ó del our: $\frac{1}{d} \cdot 0,8 d \cdot \varepsilon_{p}=0,8 \varepsilon_{p}$

Fig. 12.-GIRO POSIBLE EN EL APOYO EN CELOSIA: Se contabilizan exclusivamente las deformaciones de flexión: alargamiento del acero y acortamiento del hormigón (Ricardo AROCA, Cálculo Plástico H. A., cuaderno manuscrito por cortesía del autor).

La jornada ha sido provechosa por una vez. El señor $\mathrm{K}$ repasa sus razonamientos, ajusta sus formulaciones, reescribe las rutinas y lo deja todo funcionando. Mientras prepara y elige anzuelos y cañas, se le ocurre invitar al apacible fin de semana a su antiguo compañero de estudios.

\section{TERCERA SEMANA: LUNES}

Caminando hacia el gabinete, el señor $\mathrm{K}$ sonríe pensando en la larga conversación del fin de semana: sus tribulaciones y trabajos, las locas iniciativas empresariales de su primo, la política científica y universitaria. Su amigo se había sorpendido de sus provisionales conclusiones, y se había interesado por sus "novedosas" hipótesis: "Claro", pensó, "que está en una cátedra de acero..." Gracias sin duda a todo aquel cúmulo de informaciones, una brillante idea había surgido en su mente para el caso de que no encontrara solución a sus problemas en esta semana...

En el gabinete había suficientes resultados como para hacerse una idea bastante cabal del estado de la cuestión: con el nuevo modelo de la celosía se alcan- zaba la carga de rotura prevista en varios casos. Y siempre habia un aumento de resistencia. Su optimismo del viernes anterior se veía así confirmado (tabla 6).

El viernes siguiente era el día de la fatídica reunión. En los cuatro días que restaban había que ordenar resultados, resumir tablas, sacar conclusiones e idear algunas propuestas para la continuación del trabajo.

A estas alturas al señor $\mathrm{K}$ le resultaba evidente que los métodos de la norma eran, cuando menos contradictorios. Quedaba por ver si alguno de los métodos que él mismo había ideado era capaz de dar cuenta de esas contradicciones. El día pasó preparando programas para obtener resultados sistemáticos y poder enjuiciar globalmente el asunto.

El tiempo era el problema: si para cada una de las vigas apoyadas de la primera hora era necesaria una integración numérica, para cada una de las empotradas, en el caso de la celosía o del apoyo finito, como muy poco hacía falta una media de 10 por cada relación L/h estudiada, 60 para el total de esbelteces modelo que había elegido para cada viga: "¿Dará tiempo?" 
Tabla 6. VIGAS DOBLEMENTE EMPOTRADAS SIMETRICAS. CARGAS COMPATIBLES. APOYO EN CELOSIA. DISEÑO: MOMENTOS ELASTICOS DE EMPOTRAMIENTO PERFECTO.

UIGA EMPOTRADA: $67: 33$ HORMIGON: $f C k=200$ ACERO : $f y k=4100$

ACCIONES: $\quad \mathrm{k}=600 \mathrm{~kg} / \mathrm{m} 2$ $G c=1.5$ modelo: Parabola-Rectangulo $G 5=1.15$ modelo: $A E H-N$

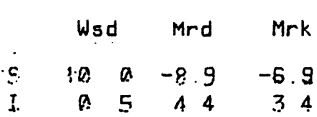
s: I $67: 33 \quad 67: 33 \quad 67: 33$

s $10 \quad 0 \quad-9.0 \quad-7.0$ $\begin{array}{lllll}1 & 10 & 5 & 4.5 & 3.5\end{array}$ S:I $67: 33 \quad 67: 33 \quad 67: 33$

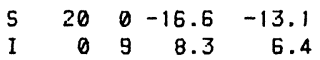
S:I $68: 32 \quad 67: 33 \quad 67: 33$

S $\quad 20 \quad 0 \quad-17.8 \quad-13.7$

I $\quad \begin{array}{llll}10 & 10 & 8.9 & 6.9\end{array}$ S:I $67: 33 \quad 67: 33 \quad 66: 34$

S $\quad 20 \quad 0-18.0 \quad-13.8$ I $\quad 20 \quad 10 \quad 9.0 \quad 7.0$ S:I $66: 34 \quad 67: 33 \quad 66: 34$

$5 \quad 30 \quad 0 \quad-23.1 \quad-18.7$ $\begin{array}{lllll}\text { I } & 0 & 13 & 11.5 & 9.0\end{array}$ S:I 69:31 67:33 67:33

$5 \quad 30 \quad 0 \quad-25.6 \quad-20.0$ $\begin{array}{lllll}\text { I } & 10 & 15 & 12.8 & 10.0\end{array}$ S:I $67: 33 \quad 67: 33 \quad 67: 33$

S $\quad 30 \quad 0 \quad-26.8 \quad-20.5$ I. $20 \quad \begin{array}{llll}20 & 16 & 13.4 & 10.5\end{array}$ $5: 1 \quad 66: 34 \quad 67: 33 \quad 66: 34$

$5 \quad 30 \quad 0 \quad-27.0 \quad-20.7$ $\begin{array}{lllll}\text { I } & 30 & 16 & 13.5 & 10.6\end{array}$ S:I $66: 34 \quad 67: 33 \quad 66: 34$

$\begin{array}{llllll}5 & 40 & 0 & -28.3 & -23.4\end{array}$ $\begin{array}{lllll}0 & 17 & 14.2 & 11.1\end{array}$ S:I $71: 29 \quad 67: 33 \quad 68: 32$

$\begin{array}{lllll}5 & 40 & 0 & -32.1 & -25.6\end{array}$ $\begin{array}{lllll}1 & 10 & 19 & 16.0 & 12.7 \\ 5.1 & 68.32 & 67: 33 & 67: 33\end{array}$

$\begin{array}{lllll}5 & 40 & 0 & -34.6 & -26.9\end{array}$ $\begin{array}{lllll}I & 20 & 21 & 17.3 & 13.7\end{array}$ S:I $66: 34 \quad 67: 33 \quad 66: 34$

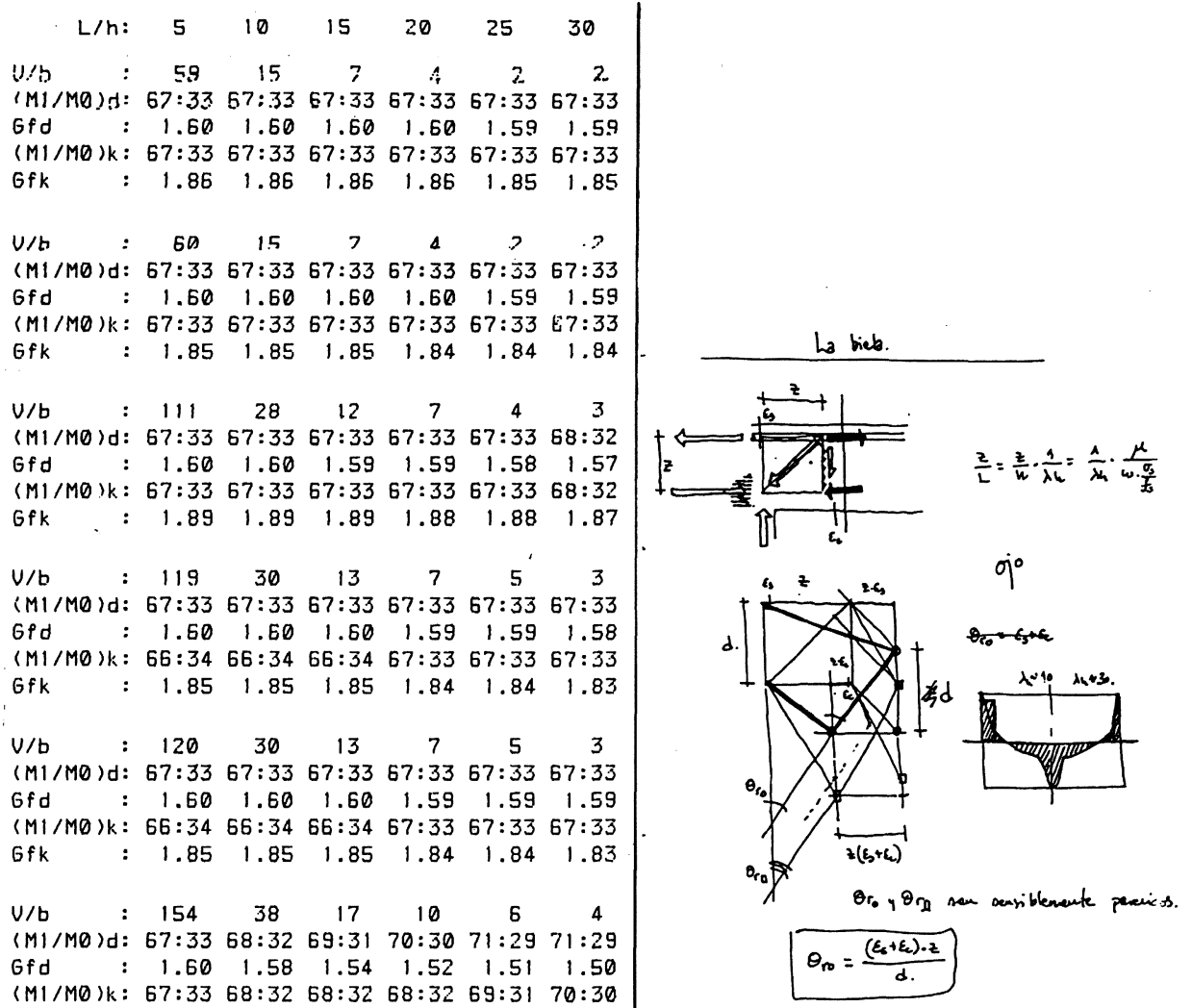

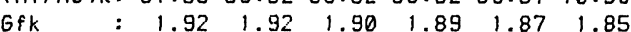
$\begin{array}{lllllllc}U / b & : & 171 & 43 & 19 & 11 & 7 & 5\end{array}$ (MI/MO)d: $67: 33 \quad 67: 33 \quad 67: 33 \quad 67: 33 \quad 68: 32 \quad 68: 32$ $\begin{array}{llllllll}\text { Gfd } & : & 1.60 & 1.60 & 1.59 & 1.59 & 1.58 & 1.56\end{array}$ (M1/MO)k: 67:33 67:33 67:33 67:33 67:33 67:33 $\begin{array}{llllllll}\text { Gfk } & : & 1.88 & 1.88 & 1.88 & 1.87 & 1.87 & 1.86\end{array}$

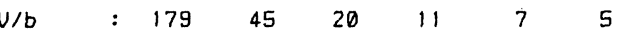
(M1/MO)d: 67:33 67:33 $67: 33 \quad 67: 33 \quad 67: 33 \quad 67: 33$

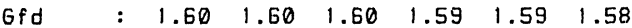
(MI/MO)k: 66:34 66:34 66:34 66:34 67:33 67:33 $\begin{array}{llllllll}6 \mathrm{fk} & : & 1.85 & 1.85 & 1.85 & 1.85 & 1.84 & 1.83\end{array}$ $\begin{array}{llllllll}U / b & : & 180 & 45 & 20 & 11 & 7 & 5\end{array}$ (MI/MO)d: 67:33 $67: 33 \quad 67: 33 \quad 67: 33 \quad 67: 33 \quad 67: 33$

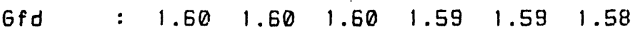
(MI/MO)k: 66:34 66:34 66:34 66:34 67:33 67:33 $\begin{array}{llllllll}\text { Gfk } & : & 1.85 & 1.85 & 1.85 & 1.85 & 1.84 & 1.83\end{array}$ $\begin{array}{llllllll}\text { U/b } & : & 189 & 47 & 21 & 12 & 8 & 5\end{array}$ $\begin{array}{llllll}\text { (MI/MO)d: } 72: 28 & 72: 28 & 72: 28 & 72: 28 & 72: 28 & 72: 28\end{array}$ $\begin{array}{llllllll}\text { Gfd } & : & 1.49 & 1.48 & 1.48 & 1.48 & 1.48 & 1.48\end{array}$ (MI/MO)k: $68: 32 \quad 69: 31 \quad 71: 29 \quad 71: 29 \quad 72: 28 \quad 72: 28$ $\begin{array}{llllllll}6 \mathrm{fk} & : & 1.95 & 1.91 & 1.87 & 1.85 & 1.84 & 1.84\end{array}$

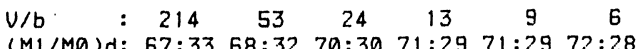
Gfd $1.50 \quad 1.56 \quad 1.53 \quad 1.51 \quad 1.501 .49$ (MI/MO)k: 67:33 67:33 67:33 $68: 32 \quad 69: 31 \quad 70: 30$ $\begin{array}{llllllll}\mathrm{GfK} & : & 1.91 & 1.90 & 1.89 & 1.86 & 1.84 & 1.82\end{array}$ $\begin{array}{llllllll}U / b & : & 231 & 58 & 26 & 14 & 9 & E\end{array}$ (M1/MO)d: $67: 33 \quad 67: 33 \quad 67: 33 \quad 67: 33 \quad 68: 32 \quad 69: 31$ Gfd $\quad: \quad \begin{array}{lllllll}1.60 & 1.50 & 1.60 & 1.59 & 1.57 & 1.55\end{array}$ (M1/MO)k: 66:34 66:34 66:34 67:33 67:33 67:33 $\begin{array}{llllllll}\text { Gfk } & : & 1.88 & 1.88 & 1.88 & 1.87 & 1.86 & 1.85\end{array}$ 
$\begin{array}{lllll}5 & 40 & 0 & -35.8 & -27.4\end{array}$ S:I $65: 35 \quad 67: 33 \quad 66: 34$

$\begin{array}{lrrrr}\text { S } & 40 & 0 & -35.9 & -27.5 \\ \text { I } & 40 & 22 & 18.0 & 14.3\end{array}$ $5: I \quad 65: 35 \quad 67: 33 \quad 66: 34$

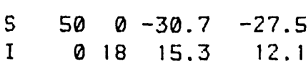

\begin{tabular}{|c|c|c|c|c|c|c|c|}
\hline$U / b$ & : & 239 & 60 & 27 & 15 & 10 & 7 \\
\hline$(M 1 / M O)$ & & $67: 33$ & $67: 33$ & $67: 33$ & $67: 33$ & $67: 33$ & $68: 32$ \\
\hline Gfd & : & 1.60 & 1.60 & 1.60 & 1.60 & 1.59 & 1.58 \\
\hline$(M 1 / M O) k$ & & $66: 34$ & $66: 34$ & $66: 34$ & $66: 34$ & $66: 34$ & $67: 33$ \\
\hline Gfk & : & 1.86 & 1.86 & 1.86 & 1.85 & 1.84 & 1.82 \\
\hline$V / b$ & $:$ & 240 & 60 & 27 & 15 & 10 & 7 \\
\hline$\left(N_{1} / M \theta\right) d$ & & $67: 33$ & $67: 33$ & $67: 33$ & $67: 33$ & $67: 33$ & $68: 32$ \\
\hline$G \mathrm{fd}$ & : & 1.60 & 1.60 & 1.60 & 1.60 & 1.59 & 1.57 \\
\hline (M1) & & $66: 34$ & $66: 34$ & $66: 34$ & $66: 34$ & $66: 34$ & $67: 33$ \\
\hline$G f k$ & 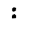 & 1.86 & 1.86 & 1.86 & 1.85 & 1.85 & 1.82 \\
\hline$U / b$ & : & 204 & 51 & 23 & 13 & 8 & G \\
\hline$(M 1 / M O) d$ & & $75: 25$ & $74: 26$ & $73: 27$ & $73: 27$ & $73: 27$ & $73: 27$ \\
\hline Gfd & : & 1.42 & 1.45 & 1.45 & 1.46 & 1.46 & 1.46 \\
\hline (MI) MO & & $73: 27$ & $73: 27$ & $73: 27$ & $74: 26$ & $74: 26$ & $74: 26$ \\
\hline Gfk & : & 1.98 & 1.96 & 1.95 & 1.95 & 1.95 & 1.95 \\
\hline U/b & : & 249 & 62 & 28 & 16 & 10 & 7 \\
\hline$(M I / M O) D$ & & $72: 28$ & $73: 27$ & $73: 27$ & $73: 27$ & $73: 27$ & $73: 27$ \\
\hline Gfd & : & 1.49 & 1.47 & 1.47 & 1.46 & 1.46 & 1.46 \\
\hline$(\mathrm{MI} / \mathrm{MO}) \mathrm{k}$ & & $67: 33$ & $70: 30$ & $71: 29$ & $71: 29$ & $72: 28$ & $72: 28$ \\
\hline$G f k$ & $:$ & 1.93 & 1.87 & 1.84 & 1.82 & 1.81 & 1.80 \\
\hline$U / b$ & : & 274 & 68 & $3 a$ & .17 & 11 & .8 \\
\hline$(M 1 / M O) d$ & & $67: 33$ & $69: 31$ & $70: 30$ & $71: 29$ & $72: 28$ & $72: 28$ \\
\hline Gfd & : & 1.60 & 1.55 & 1.51 & 1.50 & 1.49 & 1.48 \\
\hline$(M 1 / M O) k$ & & $66: 34$ & $66: 34$ & $67: 33$ & $69: 31$ & $70: 30$ & $70: 30$ \\
\hline Gfk & $:$ & 1.91 & 1.90 & 1.88 & 1.84 & 1.82 & 1.80 \\
\hline$U / h$ & : & 2.9 .1 & 7.3 & $3 ?$ & 18 & 12 & 8 \\
\hline$(M) / I$ & & $67: 33$ & $67: 33$ & $67: 33$ & $68: 32$ & $69: 31$ & $70: 30$ \\
\hline Gfd & $:$ & 1.60 & 1.60 & 1.60 & 1.58 & 1.55 & 1.53 \\
\hline$(M) / M$ & & $66: 34$ & $66: 34$ & $66: 34$ & $66: 34$ & $67: 33$ & $68: 32$ \\
\hline Gfk & . & 1.89 & 1.89 & 1.89 & 1.88 & 1.87 & 1.84 \\
\hline$U / b$ & : & 29.9 & 75 & 33 & 19 & 17 & 8 \\
\hline (MI / Me & & $67: 33$ & $67: 33$ & $67: 33$ & $67: 33$ & $67: 33$ & $68: 32$ \\
\hline$G \mathrm{fo}$ & $:$ & 1.60 & 1.60 & 1.60 & 1.60 & 1.58 & 1.56 \\
\hline$(M) / M C$ & & $65: 35$ & $65: 35$ & $65: 35$ & $66: 34$ & $66: 34$ & 67:33 \\
\hline Gfk & $:$ & 1.87 & 1.87 & 1.87 & 1.86 & 1.84 & 1.81 \\
\hline$U / h$ & : & 299 & 75 & 3.3 & 19 & 17 & 8 \\
\hline$(M) / M$ & & $67: 33$ & $67: 33$ & $67: 33$ & $67: 33$ & $68: 32$ & $69: 31$ \\
\hline Gfd & : & 1.60 & 1.60 & 1.60 & 1.60 & 1.58 & 1.55 \\
\hline$(M 1 / M O) k$ & & $65: 35$ & $65: 35$ & $65: 35$ & $66: 34$ & $67: 33$ & $68: 32$ \\
\hline Gfk & $:$ & 1.87 & 1.87 & 1.87 & 1.86 & 1.84 & 1.81 \\
\hline
\end{tabular}

\section{TERCERA SEMANA: MARTES}

"Mientras que no tengan tablas completas, más vale que no mire los resultados que vayan saliendo", pensó el señor K. Se aplicó a estudiar la tabla de vigas empotradas analizadas con los propios recursos de la normativa. Quedaba fuera de toda duda que ese modelo, es decir, el conjunto de reglas contenidas en el articulado de la EH-82, resultaba incapaz de justificar teóricamente la resistencia de las piezas que el proyectista prevé al diseñarlas. Cabian entonces dos hipótesis:

1. Que las piezas reales alcancen realmente las cargas previstas, en cuyo caso habría que encontrar un modelo que si las justificara, y que sirviera al propósito inicial de industrializar (y por tanto optimizar) las piezas del pórtico.

2. Que las piezas reales no las alcancen, pero que el redactor de la normativa haya tenido en cuenta este hecho a través de los valores fijados para los coeficientes de seguridad. De hecho, uno de los motivos para fijar sus valores es precisamente la incertidumbre en los métodos de cálculo.
Tal hipótesis era plausible: "Si el redactor sabía que armando una viga empotrada para resistir momentos en proporción 2/1, la carga de rotura real sería la correspondiente a momentos en proporción $3 / 1$, y por las razones que fuese estaba interesado en salvar la figura de los momentos de empotramiento "de toda la vida", bien podia decidir aumentar los coeficientes de seguridad necesarios en esa proporción, es decir, 5/6. En tal caso es todavía más interesante un buen modelo que al prever con más precisión la carga de rotura real (y sobre todo del lado de la seguridad) permitiera reducir los coeficientes de seguridad, con el consiguiente ahorro de material.

Sea como fuere, en ambos casos, se hacía necesario contar con modelos más precisos que, ya sea porque son concordes con las cargas de rotura previstas, ya porque permitan reducir los coeficientes de seguridad al predecir correctamente la carga de rotura real, permitieran un diseño industrial de las piezas, es decir, un cálculo ajustado y preciso. 
En todo caso, parecía como si el proyectista actuara como en el diseño de acero: se disponía un perfil con momentos resistentes dados y se esperaba que la carga de rotura fuera la que correspondía precisamente a esos momentos, aun a costa de grandes deformaciones, formación de rótulas plásticas, etc. ¿Cuánto de dúctil era el hormigón armado? Estando el ordenador tan atareado se resignó a echar mano de su calculadora y trazó curvas Momento-Curvatura. Comparadas con el aspecto del diagrama tensión-deformación del acero laminado, su "escalón" dúctil no era gran cosa, una pizca. Con unos cálculos adicionales consideró también secciones con armadura de compresión. La ductilidad podía aumentar entonces hasta alcanzar a la de la sección que teniendo sólo armadura de tracción tenía la mayor curvatura última (Fig. 13).
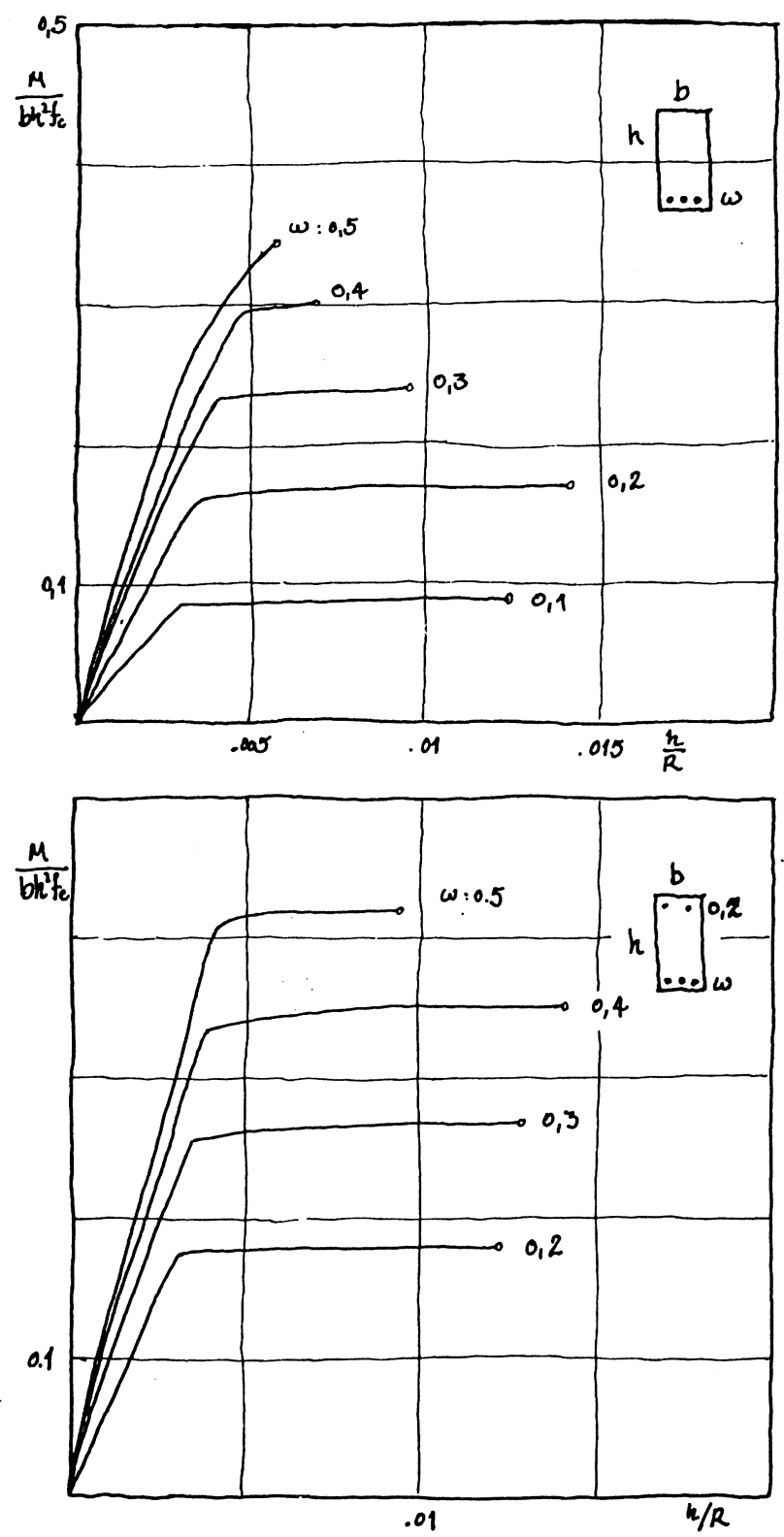

Fig. 13.-DIAGRAMAS MOMENTO-CURVATURA SEGUN CUANTIAS MECANICAS: Para el diagrama parábola-rectángulo, acero AEH4OON y hormigón H2OO.

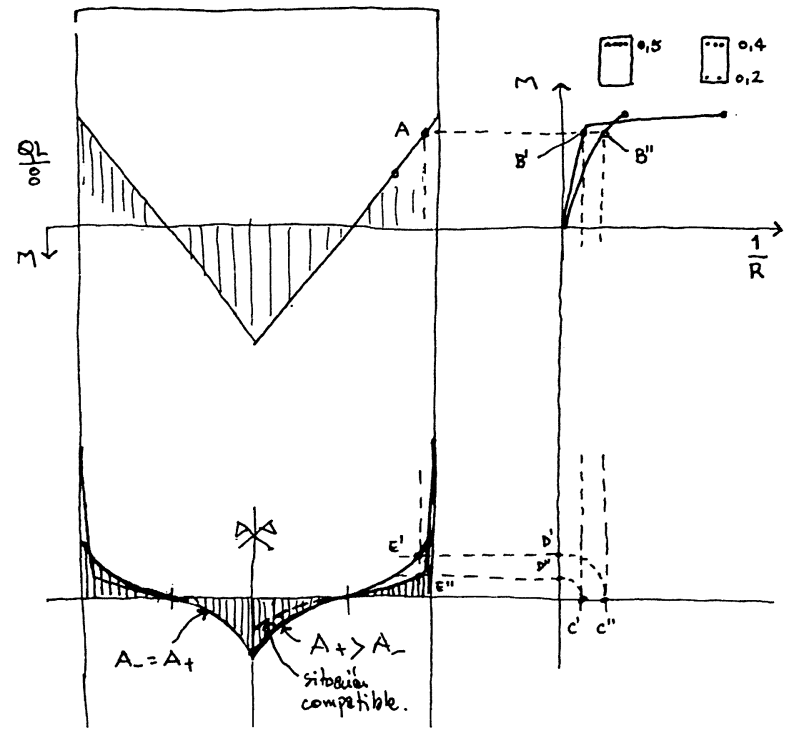

Fig. 14.-VIGA EMPOTRADA CON CARGA PUNTUAL Y APOYO DE LONGITUD NULA: Aprovechando la simetría de la pieza, en el diagrama de curvaturas se ha tramado a la izquierda el diagrama correspondiente a armaduras iguales en el extremo y en el centro de vano, y a la derecha el correspondiente al extremo con armadura de compresión.

Volvió a observar detenidamente la tabla 3: "Si unas secciones son más dúctiles que otras, las vigas correspondientes a las primeras ¿no deberían alcanzar cargas de rotura más elevadas?" No sólo no ocurría esto, sino que además ni siquiera se alcanzaba la carga de rotura de las vigas sin armadura de compresión. La angustia de días pasados volvió a embargarle: "¿Estarán mal finalmente los primeros análisis y estoy dando vueltas a lo loco?" Procurando mantenerse sereno, pensó en qué ejemplo podía resolver por sí mismo a mano. Las parábolas, transformadas por las curvas M-C, resultarían en diagramas de curvaturas muy difíciles de manejar algebraicamente, "¿y una carga puntual?". Puesto que entonces el diagrama de momentos es una recta, el diagrama de curvaturas de la viga se forma a partir de las curvas M-C sin más que el oportuno cambio de escalas (Fig. 14): "Puesto que el momento en el extremo y en el vano son iguales armaré la viga con igual cuantía superior e inferior; por tanto, en la rotura se alcanzarán las mismas curvaturas últimas y, puesto que el área de curvatura negativa es igual a la de curvatura positiva, el giro será nulo: hay equilibrio y hay compatibilidad de deformaciones: ¡Ahora sí se alcanzan las cargas previstas! ¿Qué ocurrirá si dispongo armadura de compresión en el extremo? Ahora, a pesar de que la curvatura última es mayor en el extremo que en el vano (la sección extrema es más dúctil que la central), el área de curvaturas negativas será menor que la positiva (la parte extrema es más rígida que la parte central): en consecuencia, nos quedará un giro positivo residual: no hay compatibilidad de deformaciones. Para que la haya, el momento último del vano habrá de ser algo menor, lo suficiente como para que ambas áreas se igualen, así que la carga de rotura es menor aún." 
"Ya es raro que una viga intuitivamente más dúctil sea incapaz de alcanzar la misma carga de rotura que su hermana más frágil. Pero, ductilidades aparte, lo que está en contra del más elemental sentido común es que, si con una determinada cantidad de acero alcanzo una determinada resistencia, ponga todavía más acero en la viga y la resistencia disminuya. ¡Esto clama al cielo!" El señor K durmió apaciblemente mientras los programas desgranaban lentamente el misterio.

\section{TERCERA SEMANA: MIERCOLES}

La curiosidad le pudo: aunque el programa no había acabado todos los cálculos, no pudo evitar echar un vistazo. Con ambos métodos de compatibilidad fuerte se obtenían aumentos en las cargas de rotura en relación a la obtenida planteando sólo la compatibilidad débil. $Y$ alguna vez se alcanzaba la prevista. Todo parecía indicar que esto ocurría cuando o bien la esbeltez era pequeña o bien se ponía armadúra de compresión o ambas cosas a un tiempo. ¿Podría obtener alguna razón más inteligible del porqué de ello que unos listados de ordenador?

"Veamos lo que da de sí la viga con carga puntual: empecemos por el caso de un apoyo finito y secciones igualmente armadas y sin armadura de compresión. Para los momentos "nominales» de $Q$, en realidad en el extremo no se ha llegado al momento de rotura de la sección en virtud de la inflexión de la gráfica de momentos en el apoyo (Fig. 15). No obstante, puesto que esa inflexión reduce el área de curvaturas negativas el giro final será positivo y no hay compatibilidad. Para que la haya puedo disminuir el momento del vano, reduciendo asi la carga de rotura; pero puedo también aumentar el momento "nominal" de extremo, puesto que en rigor ahi no he alcanzado la rotura. Si lo aumento hasta alcanzar realmente la rotura, la situación se invierte: es ahora menor el área de curvaturas positivas, de nuevo no hay compatibilidad. Para que la haya puedo aumentar ahora el momento del vano hasta lo que sea necesario. En esta situación, el momento isostático, es decir, la suma del momento de extremo y de vano, es mayor que el inicial, y la carga de rotura final también lo será. Puesto que cuantitativamente esto ocurre tanto más cuanto más ancho es el apoyo, y esto ocurre a su vez cuanto menos esbelta es la viga, pues el apoyo ha de soportar más carga, puedo concluir que, efectivamente, a igualdad del resto de variables la carga de rotura será proporcionalmente mayor en las vigas menos esbeltas. ¡Bien, bien!"

Análogo razonamiento cabía hacer en el caso de una viga con armadura de compresión. Ahora, además, el área de curvaturas negativas era mucho mayor que en el caso anterior. De modo que la última situación de deformación compatible ni siquiera alcanzaba el valor del momento de rotura en el extremo. Si la viga tuviera

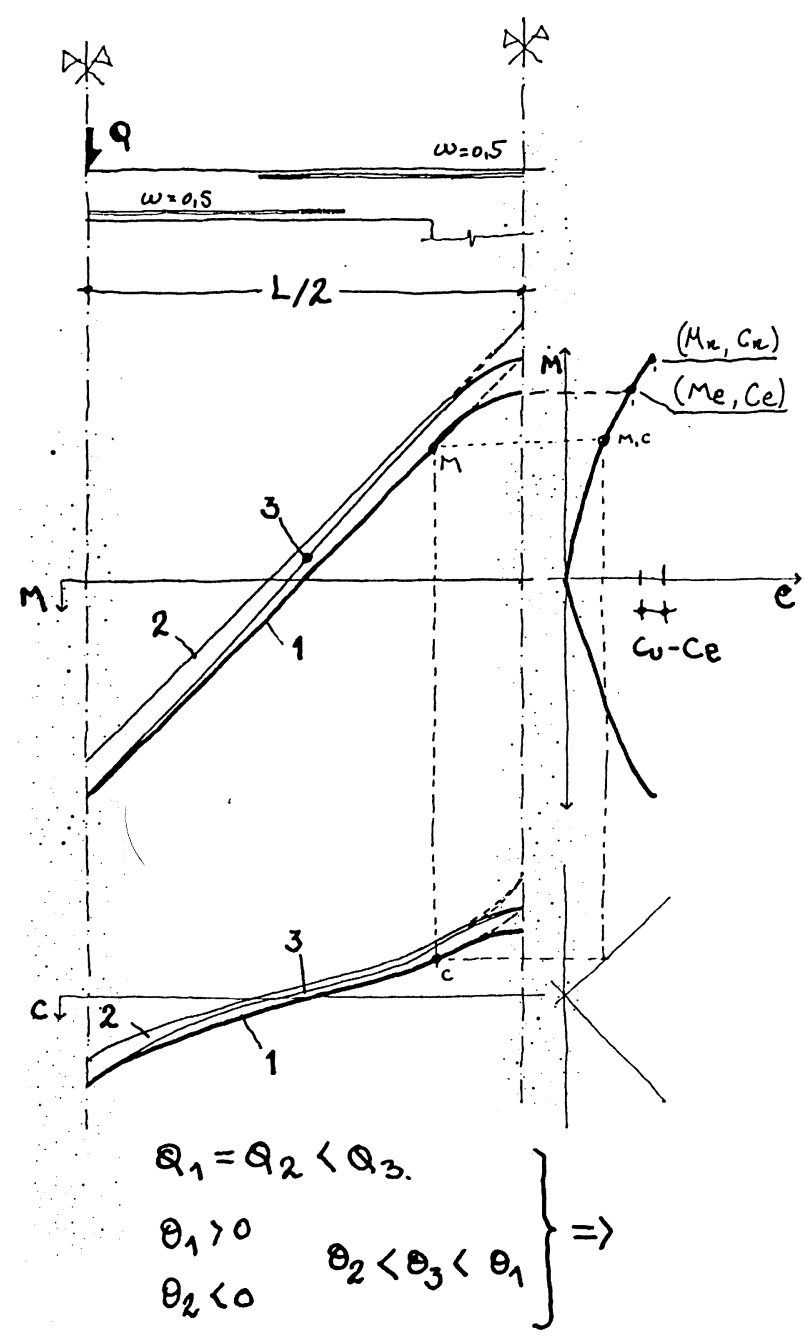

$$
\Rightarrow \text { si } \theta=0 \quad Q \geqslant Q_{1}
$$

Fig. 15.-VIGA EMPOTRADA CON CARGA PUNTUAL Y APOYO DE LONGITUD FINITA: No se dispone armadura de compresión en ninguna sección: la situación compatible se encuentra entre 1 y 2, correspondientes ambas al mismo valor de $\boldsymbol{Q}$ (igual momento isostático). La curva compatible, la 3, corresponderá siempre, cualquiera que sea, a un isostático mayor y, por tanto, a una carga de rotura mayor.

también armadura de compresión en el vano, es decir, la sección central fuera más dúctil, se óbtendria la viga más capaz de aguantar carga antes de romperse (Fig. 16).

Puesto que el crecimiento de los momentos, y por tanto de las cargas, sería tanto mayor cuanto mayor fuera la diferencia inicial entre la curvatura última del extremo y la curvatura efectivamente alcanzada, y dicha diferencia aumentaba ya fuera por una esbeltez reducida como por la existencia de armadura de compresión, si ambas condiciones se daban, la carga de rotura obtenida sería la mayor de las posibles.

Análogos razonamientos cabía hacer en el caso del modelo de celosía, y a idénticas conclusiones llegó el se- 


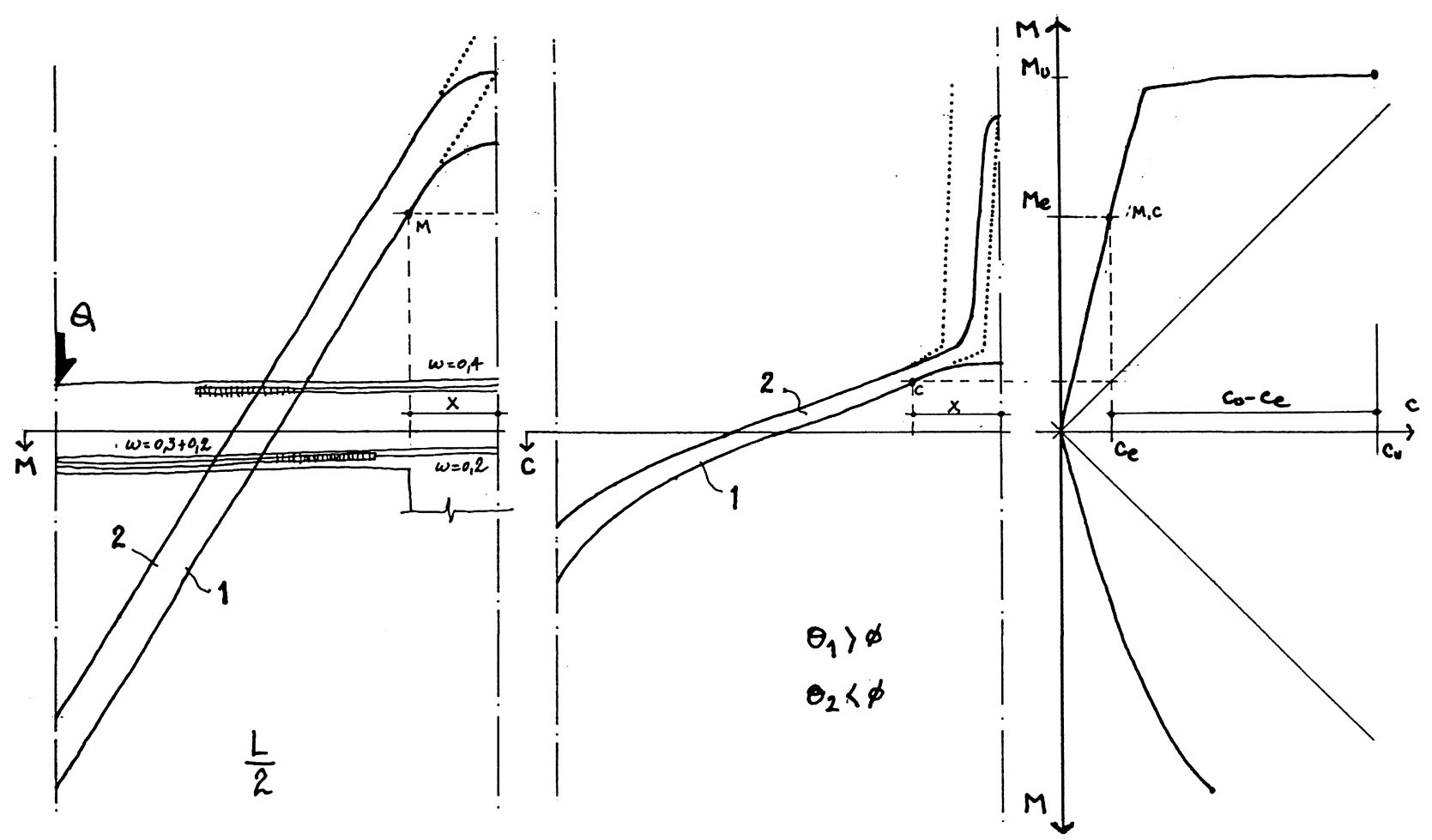

Fig. 16.-VIGA EMPOTRADA CON CARGA PUNTUAL Y APOYO DE LONGITUD FINITA: Se dispone en el extremo armadura de compresión. Se ha dibujado sólo media viga. Como en la figura 15, la situación compatible se encuentra entre 1 y 2 y corresponde a un momento isostático mayor.

ñor K. Pensó que al menos los modelos que había imaginado respetaban la intuición de que cuanto más material mayor resistencia (permaneciendo iguales el resto de las variables), intuición que ha su juicio no sólo era una ventaja económica sino que también era una verdad mecánicas.

Satisfecho, a la espera de poder ver todos los resultados sobre la mesa, recaló su mirada una vez más en los diagramas de momento-curvatura (Fig. 17). Sin saber muy bien porqué trazó verticales imaginarias que unian los puntos terminales (de coordenadas momento último, curvatura última, por tanto) de algunas de las curvas. No todas las líneas así trazadas eran ni perfectamente rectas ni verticales. Los puntos terminales que quedaron sin unir, podian unirse con dos curvas que ya había visto en alguno de los documentos que obtuvo en la universidad. Estos últimos puntos pertenecian a curvas de secciones sin armadura de compresión. Y por uno de ellos, el que correspondía a cuantía mecánica de tracción de valor 0,2 , pertenecía también

\footnotetext{
${ }^{3}$ Quizá por las prisas, en los ejemplos de la viga empotrada con carga puntual, el señor K cometió un pequeño error no exento de importancia. En efecto, razona bajo la hipótesis de que las secciones $(0,50: 0,00)$ y $(0,40: 0,20)$ alcanzan el mismo momento último: aproximadamente es asi. Sin embargo, la sección con armadura de compresión resiste algo más. Una sección de igual resistencia es, en realidad, la $(0,36: 0,16)$, con una cuantía mecánica total de acero de 0,52. Si bien este hecho no afecta a lo esencial del razonamiento si matiza sus conclusiones: no se trata sólo de a más material, más resisten. cia, sino que, también, a mejor colocación, mayor resistencia.
}

a la más diestra de las verticales trazadas: "¿Querrá esto decir algo?", se preguntó como se hubiera preguntado si hacía el crucigrama del periódico. "¿Qué propiedad tienen en común los puntos unidos por las verticales?", siguió preguntándose. "En primera instancia,

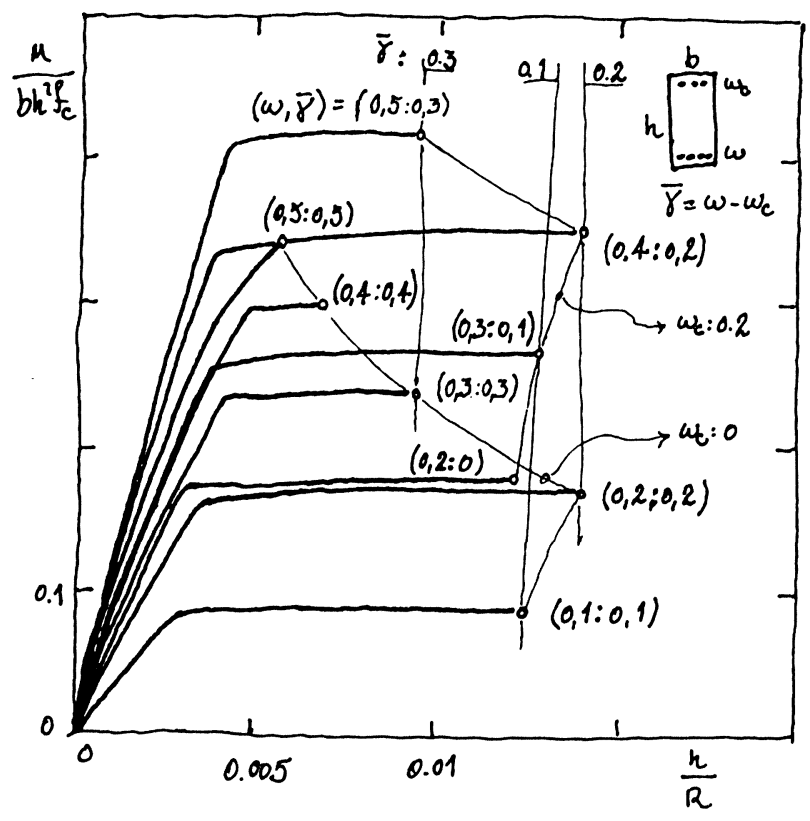

Fig. 17.-CURVATURAS ULTIMAS: Con una disposición adecuada de las cuantias, puede disponerse de secciones tan dúctiles como permitan los criterios de rotura, cualquiera que sea el momento último. La curvatura última sólo está limitada por las deformaciones de rotu. ra del hormigón, definidas convencionalmente por la normativa. 


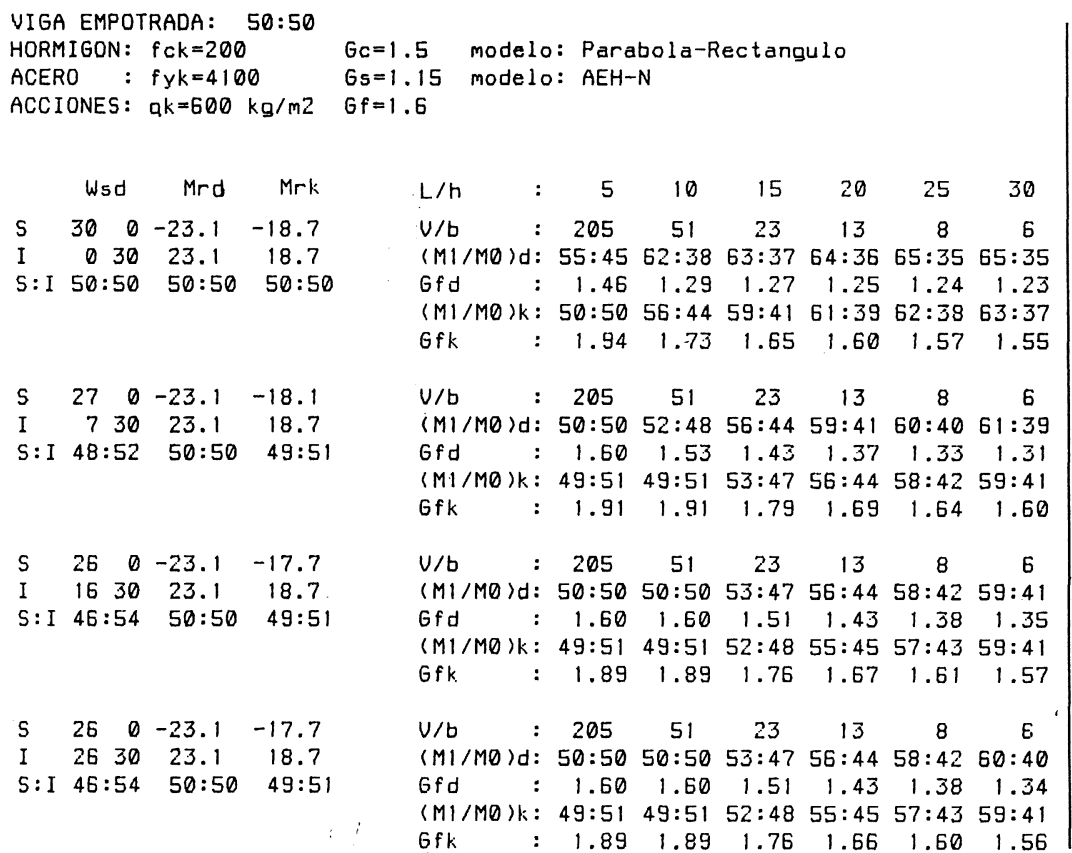

qué corresponden a los momentos últimos de secciones que, aún teniendo muy distinta cuantía tanto de tracción como de compresión, tienen la misma curvatura última. ¿Por qué? ¿Existe alguna relación entre las cuantías?" Probó con relaciones geométricas y aritméticas, tanto con las cuantías de tracción como con las de compresión: "Todas las curvas unidas por una vertical tienen una diferencia constante entre sus cuantías de tracción y de compresión. Y las de la vertical más diestra, la de mayor curvatura última, la más dúctil por tanto, tiene una diferencia de cuantías de... exactamente... ¡0,2! ¡Eureka! ¡Lo encontré!”

Efectivamente, ahora sabía que para obtener la máxima carga de rotura tendría que buscar entre las vigas menos esbeltas y de éstas, entre aquellas cuya diferencia de cuantías fuera ese mágico valor.

\section{TERCERA SEMANA: JUEVES}

El día se anunciaba agotador: esperar los últimos resultados, ordenar la información, comprobar la veracidad de sus hipótesis. Todo iba saliendo a pedir de boca, comió apenas un bocadillo.

Con todo, ¿qué podia decirle a su primo? ¿Habia avanzado algo acerca del problema fundamentalmente económico que le había encomendado? ¿Cómo optimizar diseños y productos con una normativa tan poco óptima? La única línea argumental que se le ocurría era que puesto que los momentos de diseño habituales no se justificaban desde la propia normativa vigente, la siguiente fase del trabajo podría ocuparse de calcular cuál sería la proporción de momentos que condujera a una sección de hormigón y a una distribución de armaduras que, en conjunto, resultarán ser la solución más económica para resistir unas cargas dadas. En seguida descubrió que tal propuesta era bastante tonta, pues no tardó ni dos minutos en descubrir cuál sería tal proporción óptima: "Aquella que minimice los momentos máximos, los momentos de extremo y vano por tanto, y esa proporción es simplemente igual a 1. Momentos iguales arriba y abajo, si fuera posible armar las vigas así, sería la solución más económica de las de canto y ancho constante"4 No le iba a quedar más remedio que sacar la carta que mantenía guardada en la manga desde el pasado fin de semana. Así pues, llamó a la universidad y preguntó por su amigo. Le invitó a asistir a la comida del día siguiente con su primo, justificando su invitación alegando su inseguridad sobre los temas que iba a tratar y la conveniencia de que un profesor de su prestigio criticara sus propuestas, para

\footnotetext{
4 El mágico valor es, en realidad, 0,18 para el diagrama $P$ - $R$ y las deformaciones de rotura de la EH-82. Además, si el apoyo es en celosia, el coeficiente de seguridad de "cálculo" es máximo cuando la diferencia de cuantías es 0,10 , mientras que el "característico" lo es para 0,20 (tabla 6): la curvatura última, por si sola, es una buena medida de la capacidad de rotación de la rótula, pero no de la ductilidad de la pieza. Si la diferencia de curvaturas últimas entre dos cuantias es pequeña, otros factores de menor importancia se muestran significativos, asi la rigidez tangente que ya habia jugado su papel en los ejemplos de las figuras 14,15 y 16 . En todo caso, las cargas alcanzadas con una u otra cuantía de compresión son muy similares y siem. pre resulta más económico como criterio de diseño una diferencia de cuantias de 0,20: el señor $K$, por un atajo equivocado, habia llegado al mejor valor.
} 
mejor convencer así a su primo. Riéndose para sí de la sorpresa que ambos, amigo y primo, habrían de llevarse, salió a dar un paseo, esperando hasta el anochecer para recoger los datos que hasta ese momento, el programa hubiera reunido (claro estaba que, en cualquier caso, no daría tiempo a terminar toda la tarea programada).

Al regreso, terminó de confeccionar sus tablas, recogió un poco los papeles que, poco a poco, se habian ido extendiendo por el gabinete, desconectó el ordenador ("bien ganado se tiene el descanso") y se arrellanó en el sillón a releer el producto de su trabajo. Aunque considerando las dificultades encontradas, le pareció suficiente, no alcanzaba para quedarse satisfecho: demasiadas imprecisiones terminológicas, demasiadas afirmaciones que si bien sostendria como buenas hipótesis no quedaban en ningún caso demostradas... Entre todas las lagunas que encontraba, había una que le preocupaba en extremo: "Después de tres semanas poniendo en solfa el académico pe-ele-dos. partido-por-doce, ¿por qué en sus últimos cálculos seguía diseñando la viga a partir de los momentos elás. ticos?" Por si aquello tenía todavía solución decidió repasar las referencias al cálculo plástico en acero, a ver si se le ocurría alguna idea.

Le llamaron la atención los teoremas clásicos del cálculo plástico, de los que apenas ya se acordaba. Y empezó a pensar si los momentos elásticos de empotramiento perfecto no serian, precisamente, sino un caso particular de aplicación del teorema del límite superior, del teorema estático. Leyendo más adelante le quedó claro que así era en el caso del acero, y lo sería en el caso del hormigón armado si este material fuera perfectamente elasto-plástico. Pero, entonces, "¿no convendrá probar diseños que respondan a proporciones 1/1 para los momentos, y ver si con los modelos propuestos se alcanza o no la carga de rotura prevista? Si se alcanzara podríamos justificar la elección de los diseños económicamente más ventajosos". Por si acaso daba tiempo todavía durante la noche, retocó lo necesario en los programas, y dejó calculándose unos pocos casos. "Si funciona, lo usaré mañana como primicia."

\section{TERCERA SEMANA: VIERNES}

Su alegria fue enorme: aunque eran pocos casos analizados, las vigas 50:50 no parecian comportarse mucho peor que las vigas 67:33. Esto podía dar un giro de ciento ochenta grados al artículo 29 de la norma: no debería decir ya "la determinación de las solicitaciones se efectuará..., etc.", si no más bien "las solicitaciones se determinarán arbitrariamente, comprobándose posteriormente que el diseño propuesto es capaz de alcanzarlas antes de la roturas".
"Bien", pensó el señor K, "es la hora". Paseó a través de un día ya otoñal hacia el restaurante donde se habian citado, algo nervioso ante lo que habría de ocurrir. Su primo y su amigo ya estaban allí. Ambos a la vez, no se conocian, se acercaron a saludarle. Después de las presentaciones, su primo fue directo al tema, como era su costumbre:

\section{-_Bien, ¿qué me cuentas?}

Tras un brevísimo silencio dictado por la indecisión, comenzó a relatar simplemente el decurso de estos últimos 21 días, sus dificultades, sus descubrimientos. Observaba con preocupación el progresivo avinagramiento de la cara de su primo conforme avanzaba en la exposición. Cuando hubo acabado, ya por los postres, su primo le inquirió como si se tratase de un fiscal más que de un empresario:

_“¿Algo más que añadir?”

-“No, esto es todo", respondió.

-"Pues en tal caso, no acierto a comprender qué es lo que me propones en realidad", respondió su primo.

-"En realidad mi propuesta es muy simple: Sinceramente pienso que tal y como está la normativa no es todavía tiempo de industrializar nada. Lo que te propongo es que tu empresa, yo y la universidad solicitemos un proyecto de investigación a la CAYCIT. Esa inversión sí te resultará rentable."

Su amigo, tan sorprendido como su primo, no pudo por menos que exclamar su acuerdo, le parecía una brillante y oportuna idea. A su primo costó un poco más convencerle, pero eso corrió ya por cuenta de su amigo y de su optimismo de investigador casi a punto de obtener financiación. "Este champán está bien bueno", penso para sí el señor K, mientras sus dos amigos discutían acaloradamente los detalles.

\section{EPILOGO}

Año y medio después de estos extraños sucesos, el proyecto de investigación esta en marcha, después de haber sido aprobado por la Comisión Asesora. Hasta donde sabemos, se han ido confirmando las hipótesis iniciales, aun cuando todavia es pronto para establecer un juicio definitivo. En todo caso, parece que el champán degustado cuando se supo la noticia de la aprobación, supo mejor aún.

Madrid, junio de 1987

\footnotetext{
5 Una redacción algo más rigurosa seria: "Las solicitaciones se de terminarán con la condición de que formen un sistema en equilibrio con las acciones, comprobándose que la estructura es capaz de al. canzarlas en su historia de cargas antes de que sobrevenga la rotura."
} 